\title{
الرؤى والأحلام السردية (دراسة في الوظائف)
}

\author{
م.د.غانم حميا عبودي \\ اختصاصي تربوي - قسم الإثراف الاختصاصي / تربية ميسان \\ رقم الموبايل: 07703247001
}

البربد الاكتروني: Ghanem.1971@yahoo.com

ملخص البحث

لم تأخذ الأحلام السردية حصتها من البحث بصورة كافية، على الرغم من أن الأدب، شعراً ونثراً، زاخر

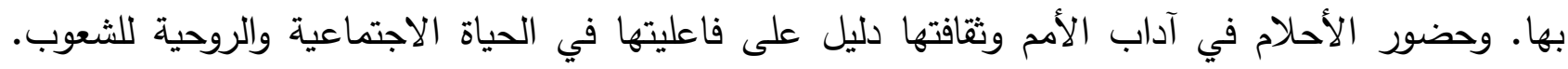

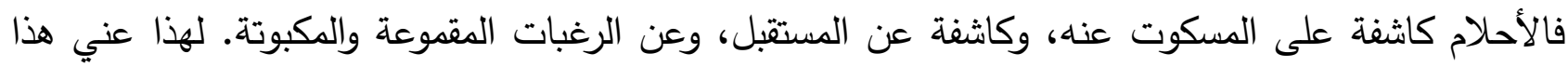

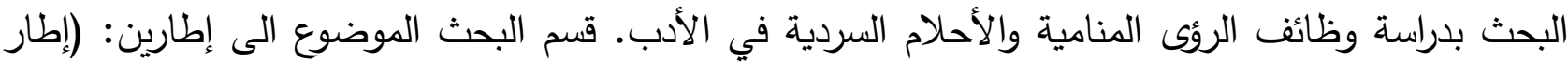

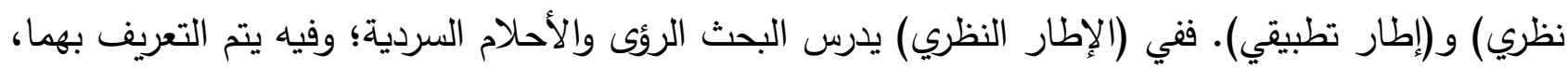

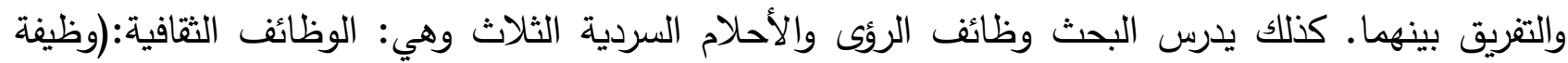

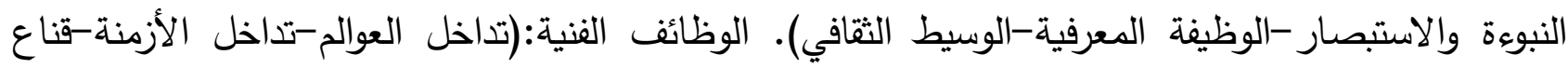

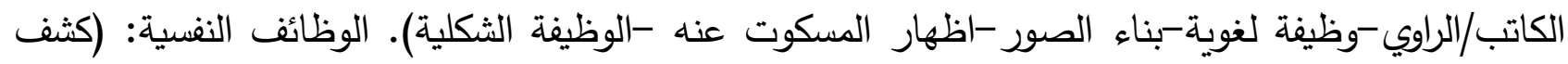

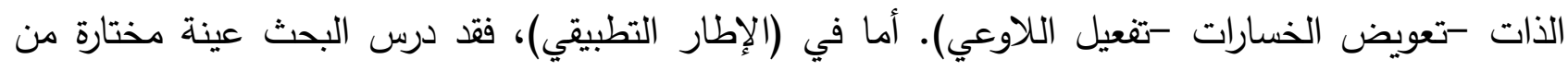

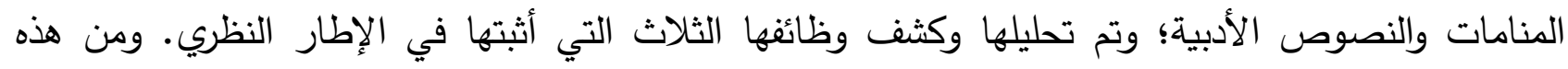

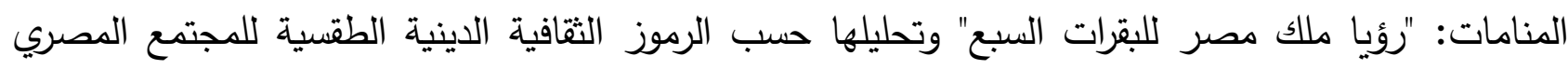

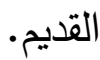

كنلك درس البحث الرؤى والأحلام السردية في الأدب في "ملحمة جلجامش" و"سيرة ابن هشام" و"حكايات ألف ليلة وليلة". كذلك درس البحث نماذج مختارة من النصوص السردية الروائية، ولا سيما في الرواية العراقية لكثف وظائف الأحلام السردية فيها.

الكلمات المفتاحية: الأحلام-الوظائف-الأحلام السردية. 
هبلة أبحاث هيسان، الجبد السابع عشر، العدد الرابع والثلاثون، كانون الأول، السنة 2021 https://doi.org/10.52834/jmr.v17i34.83

Narrative visions and dreams( a study of their functions )

\author{
Dr. Ghanim Hameed Abboodi \\ Profession \&Workplace: senior education specialist \\ educational specialist supervision dept . in Missan \\ Ghanem.1971@yahoo.com
}

Abstract:

Narrative dreams have not sufficiently been given their deserved share of the research, although literature, poetry and prose, abounds it the presence of dreams in the etiquette of nations and their culture is evidence of their effectiveness in the social and spiritual life of peoples. Dreams reveal what is not told and disclose the future, and the suppressed and pent-up desires. That is why this research examines the functions of developing visions and narrative dreams in literature The research paper is divided into two parts: theoretical and applied frameworks. In the theoretical framework the paper deals with narrative visions and dreams; in this part the definition and the difference between them are clearly presented. The research also examines the functions of the three narrative dreams and visions which are Cultural functions: (the function of prophecy and foresight - the cognitive function the cultural mediator) ; Technical functions: (overlapping worlds chronological overlapping- writer/ narrator mask); linguistic function : building pictures - showing the untold - the formal function ; Psychological functions: (self-disclosure, compensation for losses, unconscious activation ) As for the applied framework, the study deals with a selected sample of dreams and literary texts. It was analyzed and disclose the three functions that has been proved in the theoretical framework. Among these dreams: "The vision of the king of Egypt for the seven cows" which was analyzed according 


\section{هبلة أبحاث هيسان، المبلد السابع عشر، العدد الرابع والثلاثون، كانون الأول، السنة 2021}

https://doi.org/10.52834/jmr.v17i34.83

to the ritual religious cultural symbols of ancient Egyptian society The research also examines narrative visions and dreams in literature in "The Epic of Gilgamesh", "The Biography of ibn Hisham" and "Tales of a Thousand and One Nights". Finally, the research also studies selected models of narrative texts, particularly in the Iraqi novel to reveal the functions of narrative dreams in them.

Keywords: dreams -functions - Narrative dreams.

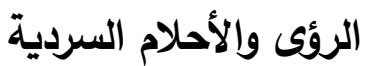

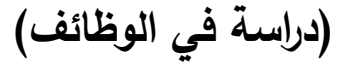

الإطار النظري

1-الرؤى المنامية

تخترق الأحلام ثقافة الأمم وآدابها عرضاً وطولاً؛ لأنها تمثل الحياة النفسية والروحية للإنسان. ففي الثقافة

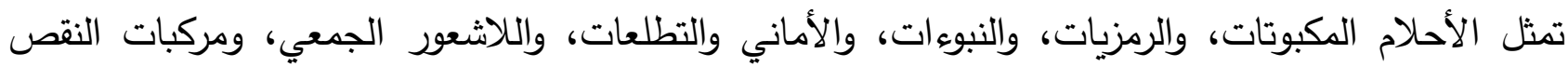

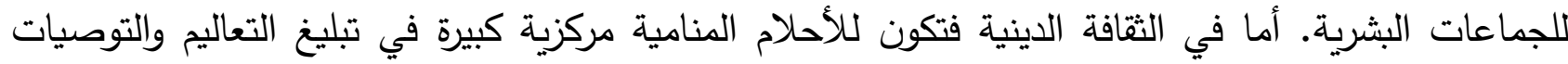

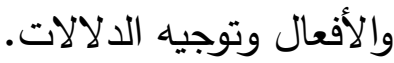

تثير لفظة "الرؤيا" الى المفهوم "القلبي"؛ أي المتخيل والماورائي. أما لفظة "رؤية" فتشير الى المفهوم

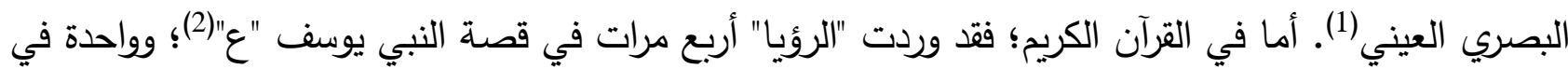
النبي إبراهيم "ع"(3)، واثنتان للنبي الكريم محمد "ص"(4). وهذه الرؤى السبع أحدثت تغييراً في مجرى الأحداث 


\section{هبلة أبحاث هيسان، المبلد السابع عشر، العدد الرابع والثلاثون، كانون الأول، السنة 2021 \\ https://doi.org/10.52834/jmr.v17i34.83}

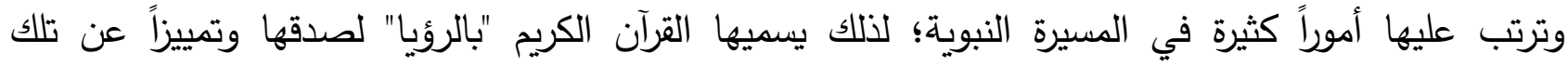
"الأحلام المنامية" الفاقدة للمعنى التي يسميها القرآن الكريم على لسان المعبرين بـ"أضغاث أحلام".

تؤدي الأحلام المنامية في الثقافة الاجتماعية/السوسيوثقافية وظائف ثقافية وآليات فنية كبيرة يسعى البحث

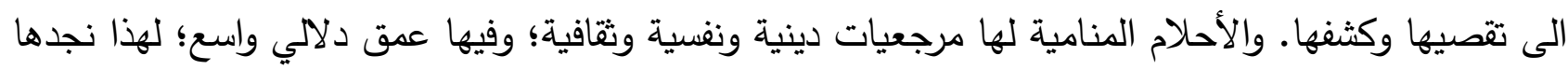

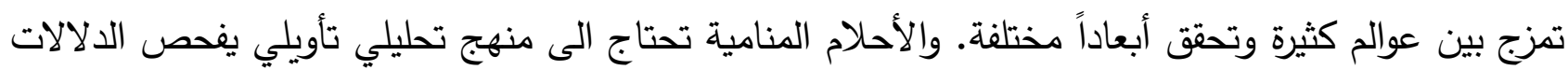
والوظائف الثقافية لها.

و"الرؤى المنامية" يمكن أن تكون مادة أدبية يتم تحليلها وتأويلها والبحث عن رمزيتها ودلالتها في الثقافة؛

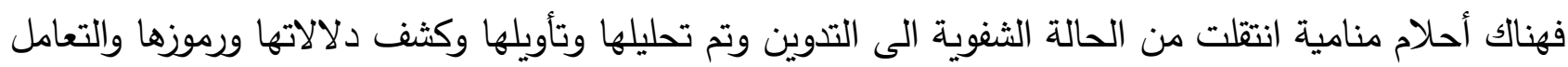

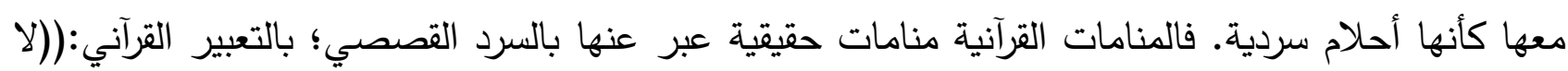

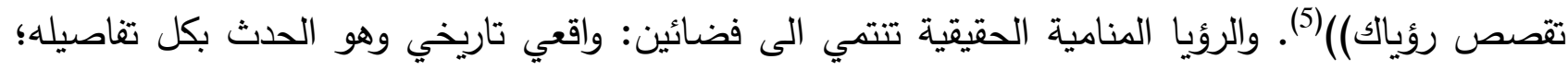
وفضاء سردي أدبي، وذلك حينما يشرع الحالم بقص الرؤيا واستخدام جميع المؤثرات السردية لإيصال ثيمة الرئية الرؤيا وإبلاغياتها. وهو ما يسميه "إمبرتو إيكو" (بالسردية الطبيعية والسردية الاصطناعية) (6)؛ يقول سعيد بنكراد تعليقاً على هاتين السرديتين: "السردية الطبيعية مرتبطة بالفعل الذي يحكي سلسلة من الأحداث وقعت فعلاً إلاً..تقابلها

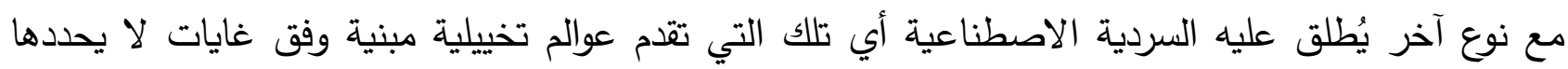
سوى المحفل المنتج للنص السردي"(7).

تحتاج المنامات الى "مُعَبِّرِين" يمتلكون أدوات ومهارات خاصة لتقسير تلك المنامات وتأويلها؛ وهناك

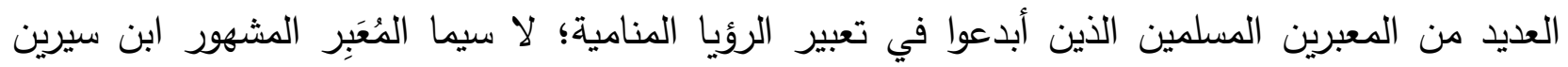

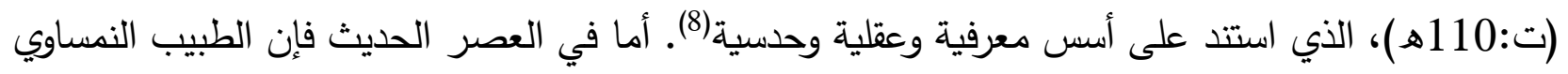
سيجموند فرويد(ت:1939م) قد جعل الأحلام نافذة لكثف اللاوعي الإنساني الذي يختزن الدكبوتات

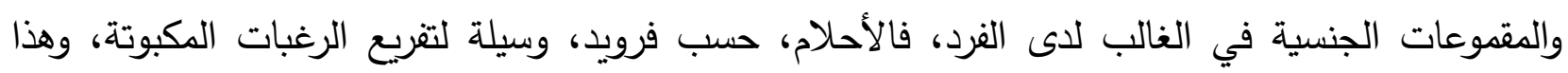




\section{هبلة أبحاث هيسان، المبلد السابع عشر، العدد الرابع والثلاثون، كانون الأول، السنة 2021 \\ https://doi.org/10.52834/jmr.v17i34.83}

التحليل الفرويدي انعكس على حقل الأدب أيضاً وأثّر فيه، فقد حدث تلاقح بين التجربة المنامية وبين التجربة

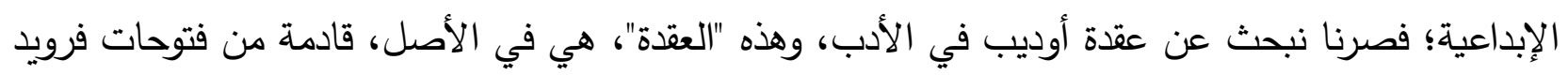

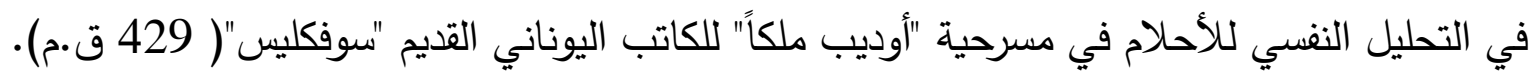

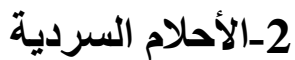

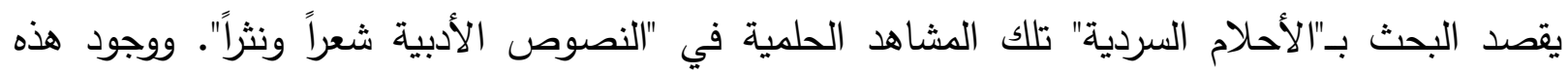
الأحلام في المتون الأدبية يأتي لغايات سردية يتطلبها بناء النص الأدبي وعوالمه المتخيلة؛ لذلك تسهم الأحلام

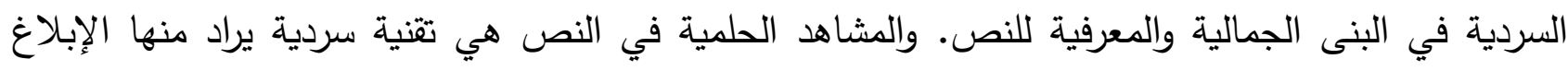
وتعميق الفكرة وخلق أجواء نفسية تتسجم مع ثيمة النص وتأويل شفراته السردية.

تتنمي الأحلام السردية الى "السرد العجائبي" الذي يخترق الأسباب الطبيعية؛ لانتمائها الى زمان ومكان

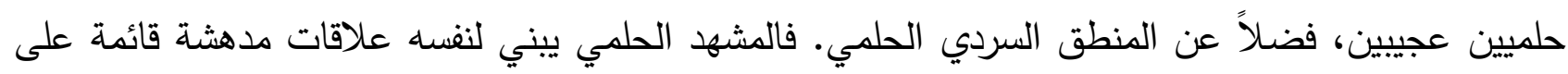

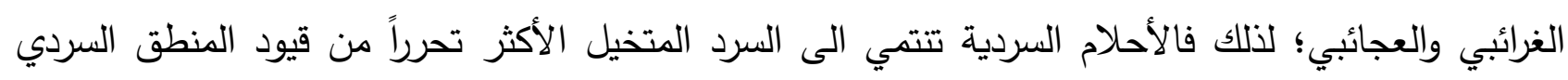
وضوابطه التخييلية.

ومشاهد الأحلام السردية ناتجة من سرديات عجائبية قديمة؛ ففي الثقافة الإسلامية، يعد النص العجائبي

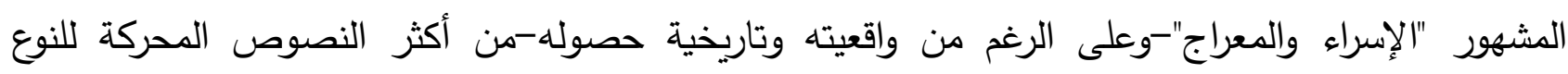

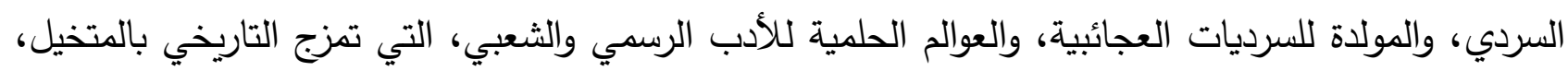

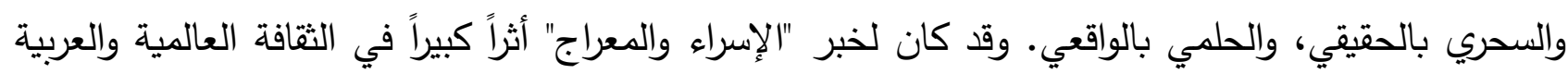

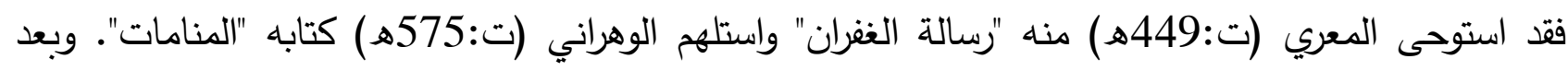

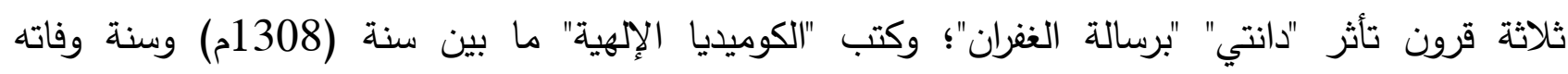
(1321م). و"الكوميديا الإلهية" ملحمة شعرية تتحدث عن رحلة خيالية قام بها دانتي الى الجنة والجحيم؛ وهذه الرحلة تحاكي رحلة المعري الخيالية.

الفرق بين الرؤى والأحلام السردية

ينبغي الفرز بين الرؤى (المنامية) التي تتنمي الى الحقيقي والتاريخي؛ وبين تلك الأحلام المتخيلة السردية

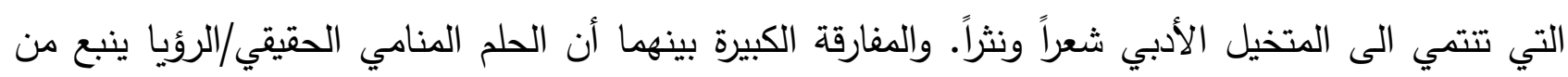




\section{هبلة أبحاث هيسان، المبلد السابع عشر، العدد الرابع والثلاثون، كانون الأول، السنة 2021 \\ https://doi.org/10.52834/jmr.v17i34.83}

اللاوعي؛ بينما الحلم المتخيل ينبع من الوعي(9). أي أن فعل المنامات يكون خارج إرادة الإنسان واختيار؛؛ لأن

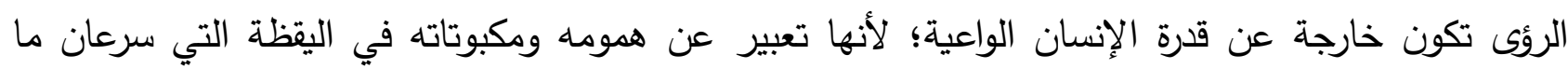
تظهر في منامه.

بينما الأحلام السردية هي فعل كتابي إبداعي من مقصديات السارد أو الثاعر ؛ يعمد إليها المبدع من أجل

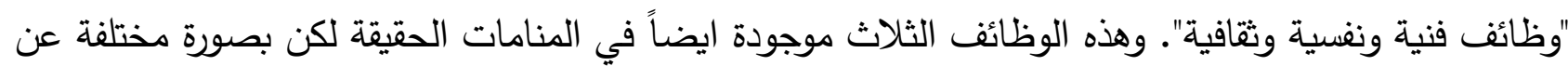

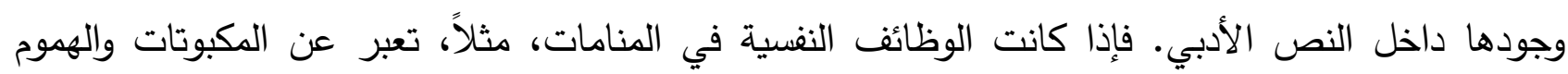

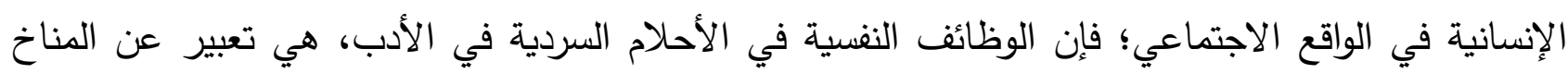

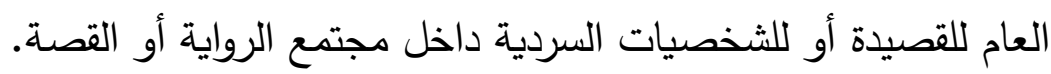

والأحلام السردية لا تحتاج الى "معبرين"؛ بل تحتاج الى "نقاد" يمتلكون أدوات النقد والتحليل الأدبي؛ من التصن

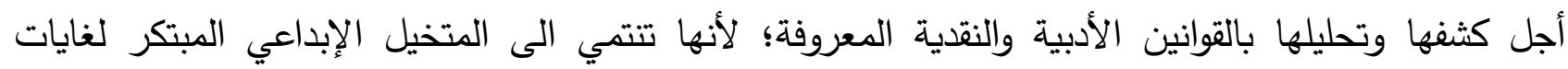

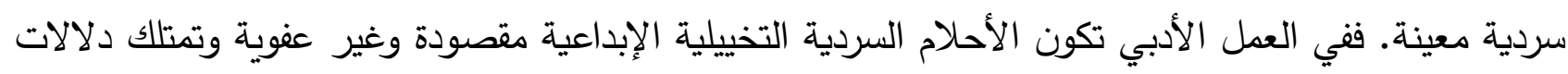
وشفرات تأويلية تكتمل بها ثيمة العمل الأدبي ويكتنز بها المشهد السردي، وتكون انتقائية تهتم بأثياء وتهمل

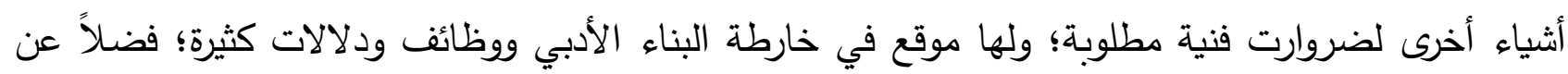

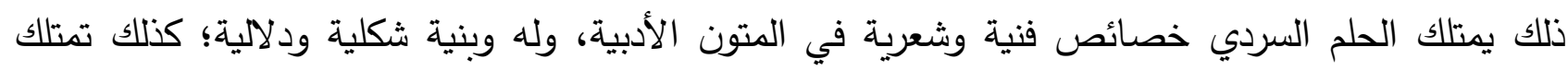
الأحلام السردية شبكة رموز ثقافية ودلالية قابلة للتأويل وآلياته المنهجية.

\section{وظائف الرؤى المنامية والأحلام السردية}

عند دراسة الوظائف يتم التعامل بين "الرؤى والأحلام السردية" بوصفهما بنية سردية واحدة، لهما وظائف مشتركة في النص أو في المنام. وهذه الوظائف هي: "وظائف ثقافية"، و"وظائف فنية"، و "وظائف نفسية". لكن في الرؤى المنامية تكون "الوظائف الثقافية" لها مركزية كبيرة في توجيه الرؤى ودلالاتها؛ لأن الرؤى التي

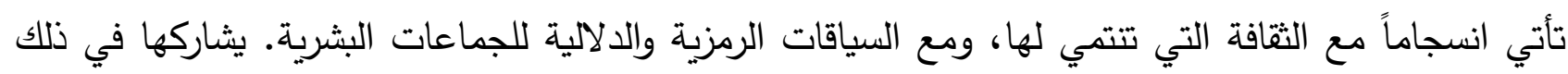
الثعر ذي الطابع الملحمي الذي يعتني بالوظائف الثقافية فضلاً عن الوظائف الجمالية الأخرى. 


\section{هبلة أبحاث هيسان، المبلد السابع عشر، العدد الرابع والثلاثون، كانون الأول، السنة 2021 \\ https://doi.org/10.52834/jmr.v17i34.83}

أما الأحلام السردية في الأدب فتعتني بالوظائف "الفنية والنفسية" أكثر من عنايتها "بالوظيفة الثقافية"؛ لكون

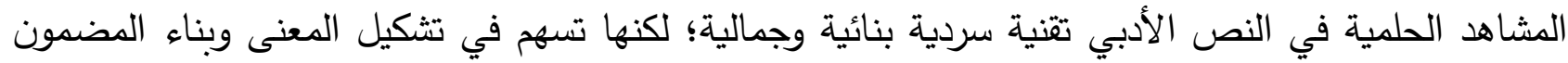

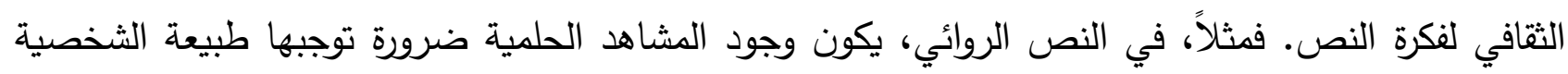

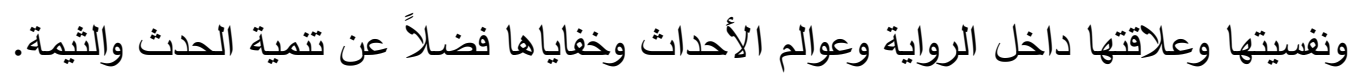

\section{الوظائف الثقافية}

تحقق المنامات والأحلام السردية الوظائف الثقافية الآتية:

1-وظيفة النبوءة والاستبصار: تحضر النبوءة في الرؤى المنامية وفي الشعر ذي الطابع الملحمي؛ وتحقق

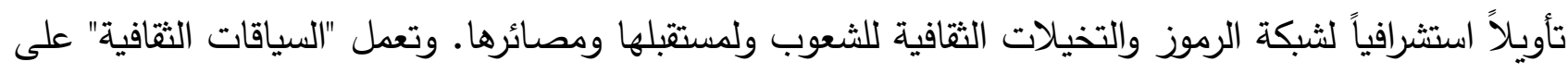

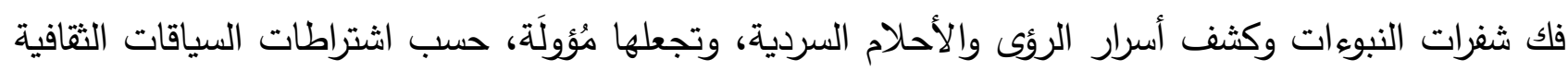
السائدة والمهيمنة. مثلما حصل في تقسير النبي يوسف "ع" لرؤيا ملك مصر القديمة؛ فقد تحققت النبوءة احتكاماً

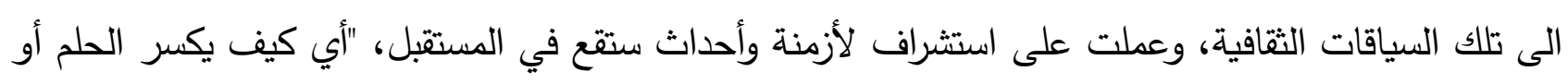

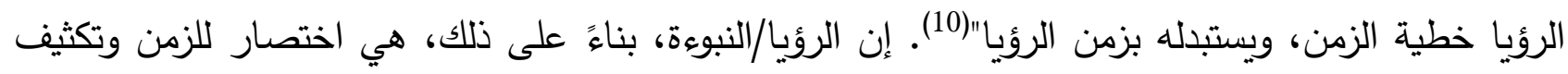

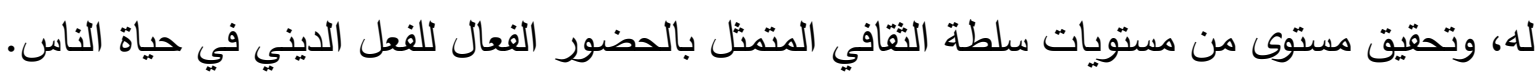
فمثلا، عملت الرؤى التبشيرية قبل بعثة النبي محمد "ص وآله" على ولادته "نصياً". وإنعاش مفهوم النبوة

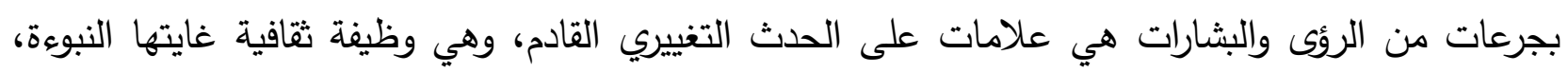
والاستكثاف، والاستعداد الثقافي للبعثة الثريفة. وهي بذلك تحقق دعم النبوة وتحصينها ورعايتها ولفت

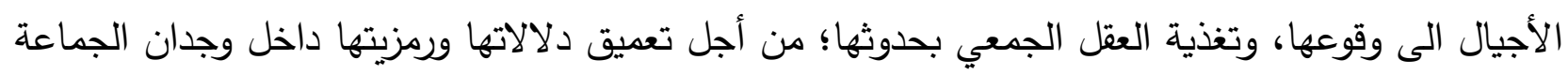

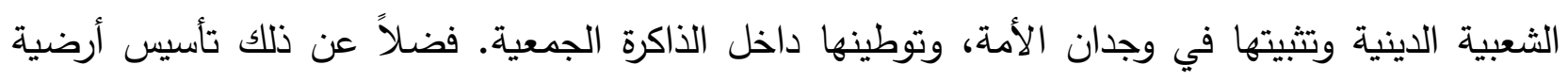
ثقافية للتبشير بها واستنباتها في الثقافة القادمة.

2-وظيفة معرفية: يقدم الأدب بجناحيه، النثر والثعر ، الوظيفة المعرفة الجمالية ذات الطابع التأثيري وهي

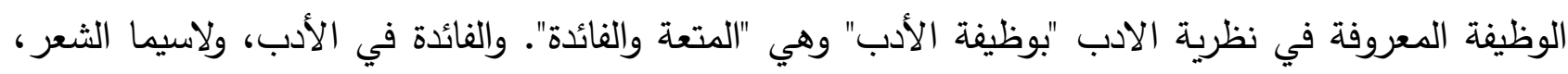

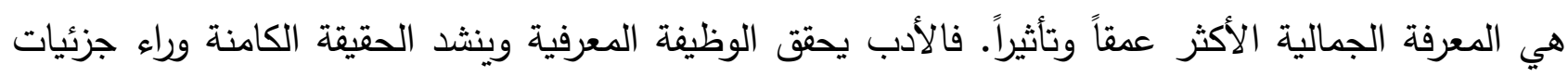
الواقع، مثلما يذهب أرسطو (11). 


\section{هبلة أبحاث هيسان، المبلد السابع عشر، العدد الرابع والثلاثون، كانون الأول، السنة 2021 \\ https://doi.org/10.52834/jmr.v17i34.83}

نعني بالوظيفة المعرفية في الرؤى والأحلام: الكثف عن الذات وعن تطلعاتها المعرفية. فالرؤى الصادقة

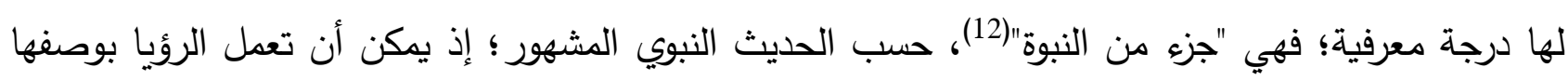

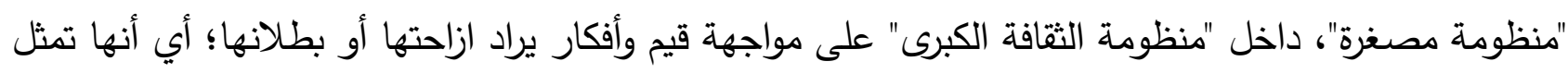

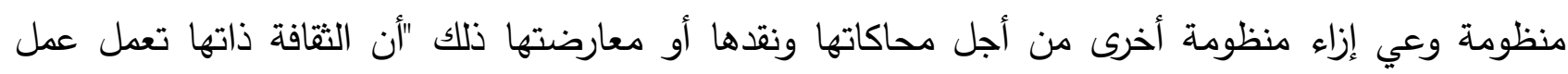

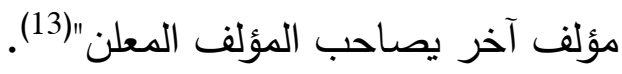

3- الوسيط الثقافي: تحقق الرؤى والأحلام تواصلاً معرفياً بين عالم الحياة في اليقظة وعالم الأحلام في

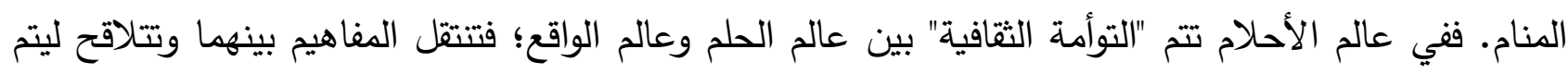

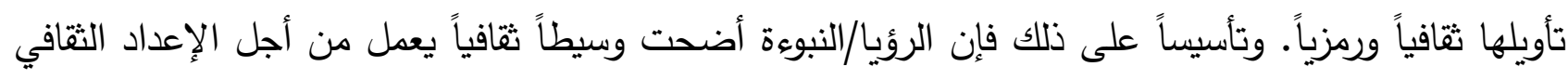

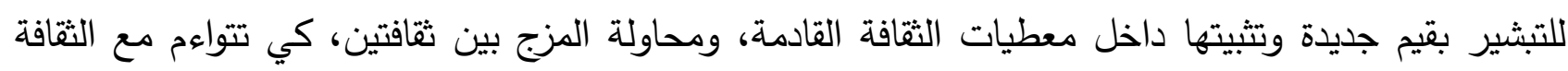

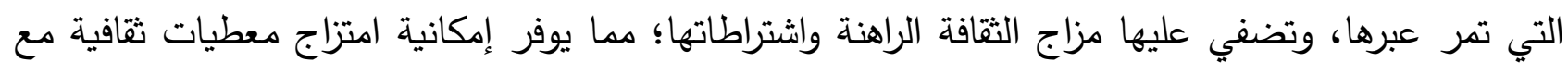
معطيات ثقافية أخرى خوفاً من القطيعة المعرفية بينهما. مثلما حصل في المثال الذي ذكرناه سابقاً، وهو

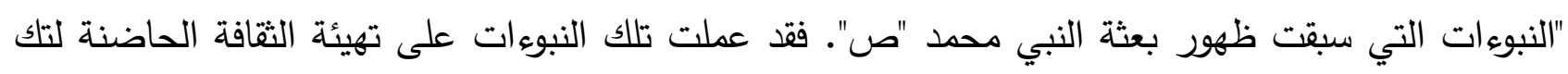
الديانة الإسلامية التغييرية الكبيرة، ومدت جسور التواصل المعرفي بين ثقافة جاهلية مشركة وبين ثقافة توحيدية

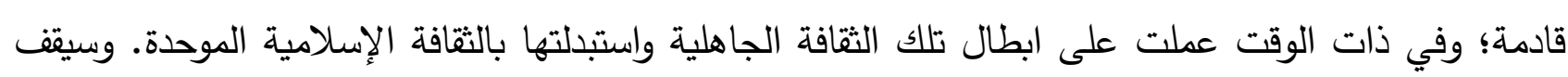

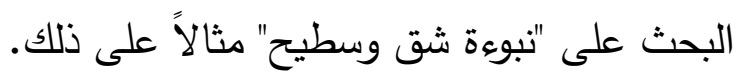

\section{الوظائف الفنية}

1-تداخل العوالم: تحقق الرؤى والأحلام السردية "منطقاً سردياً حلمياً" ناتج من التداخل الفني بين عوالم

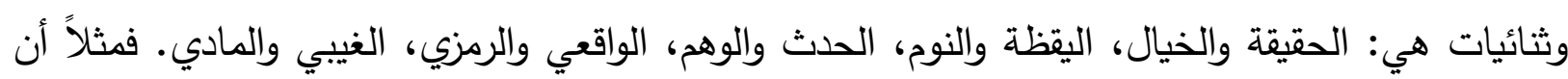

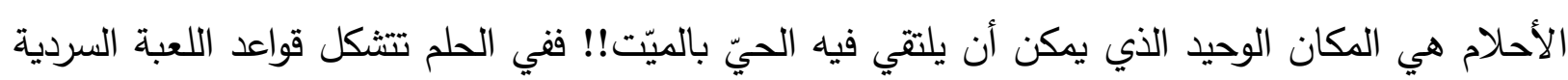

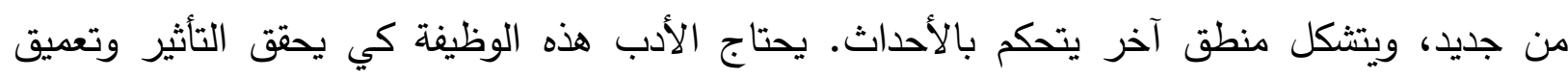

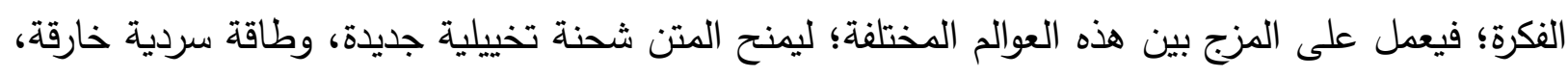
فضلاً عن مفاتيح تأويلية جديدة لثيمة النص تعمل على التشويق والإمتاع وبناء الحدث. 


\section{هبلة أبحاث هيسان، المبلد السابع عشر، العدد الرابع والثلاثون، كانون الأول، السنة 2021 \\ https://doi.org/10.52834/jmr.v17i34.83}

"في "الحلم" يُكسر المنطق السردي، فيحصل في فضاء الحلم عقد جديد بين القارئ والمؤلف بأن كل شيء

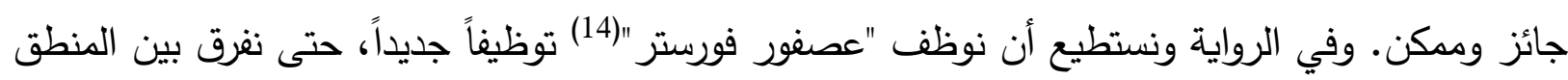

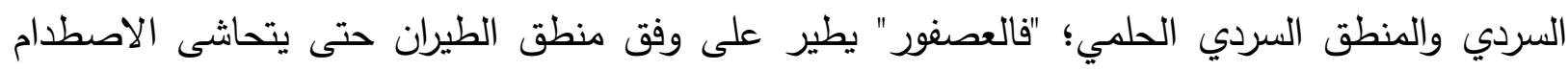

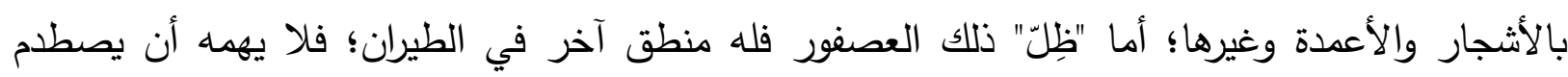

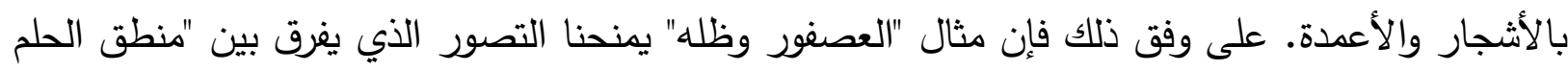

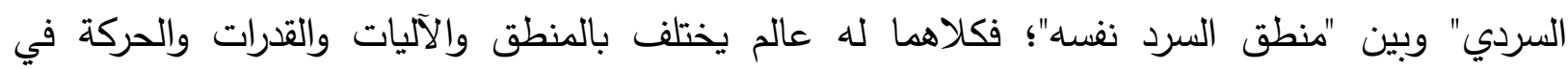

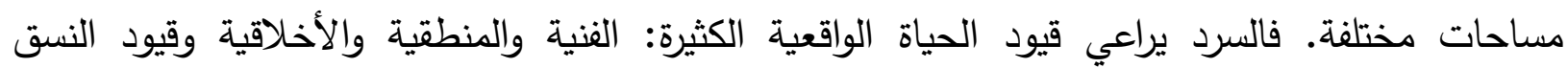
الاجتماعي والنسق الديني؛ أما الأحلام السردية فهي "ظل السرد" الذي يتحرر من ذلك الكياه المنطق الفني الصارم، فالأحلام تكسر القيود السردية وتتحرر منها وتكتسب طاقة متخيلة تدخل بها منطقة العجائبي والمستحيل؛ فيكون كل شيء ممكن وجائز .

2-تداخل الأزمنة: في الزمن الحلمي يحقق النص الذي يوظف الأحلام زمنين: "زمن السرد"، وزمن متخيل

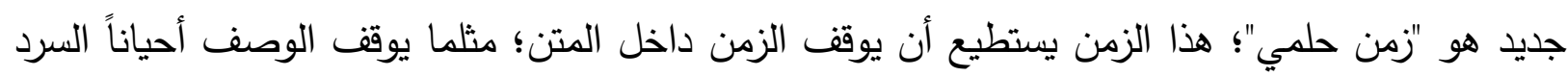

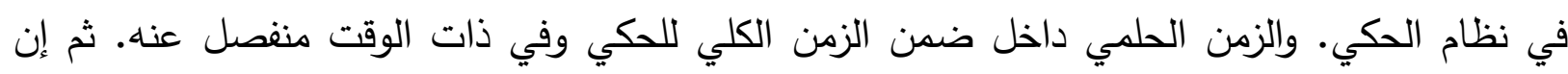

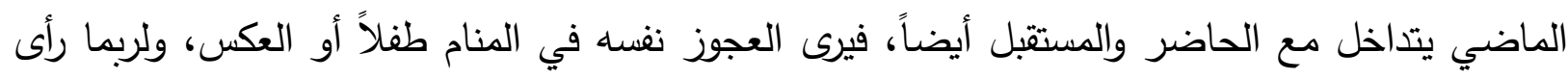

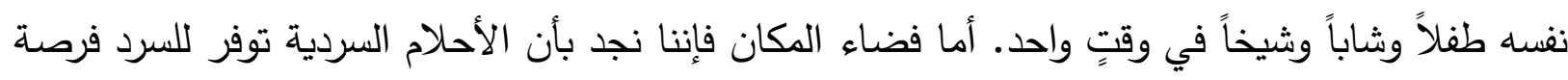

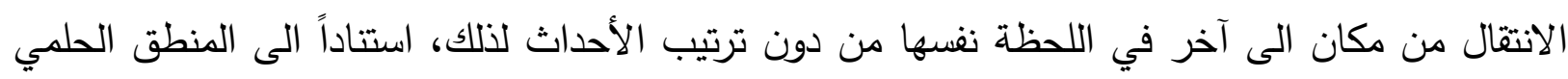

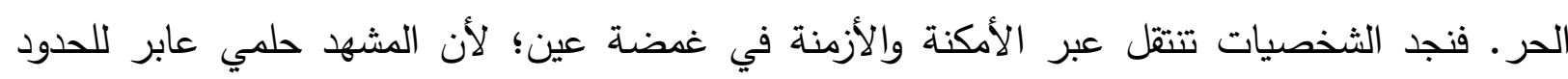

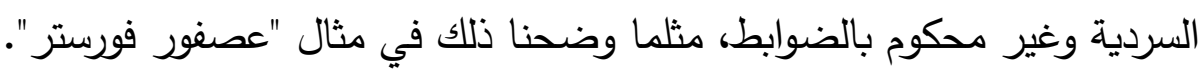

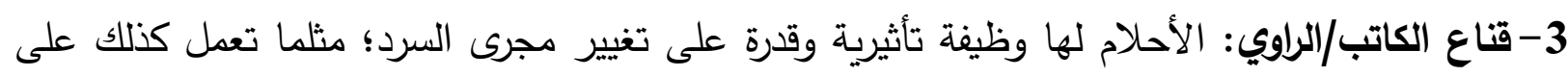

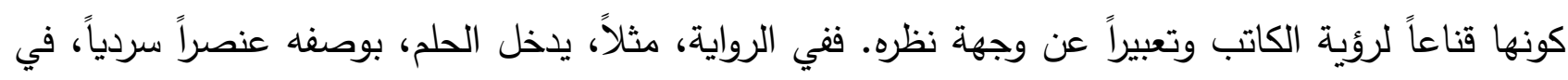

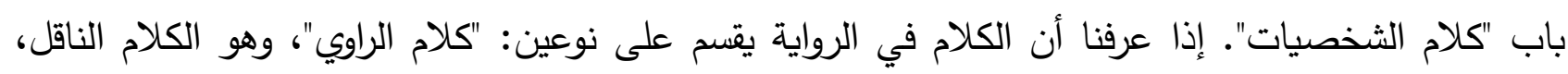

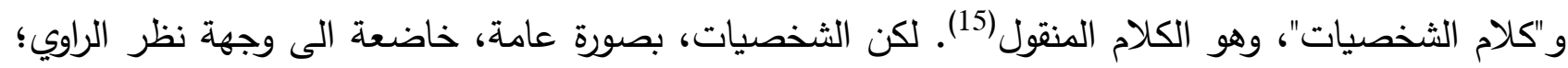
لهذا نجد حوارها حوارها وأحلامها يعملان على تفريخ مكبوتات الراوي والتعبير عن موقعه داخل الحكي؛ فالأحلام السردية تمنح الراوي مساحة للتعبير عما يعتمر من خلجات نفسه ووجهات نظره في تأويل الحدث وتفعيره، مثلما 


\section{هبلة أبحاث هيسان، المبلد السابع عشر، العدد الرابع والثلاثون، كانون الأول، السنة 2021 \\ https://doi.org/10.52834/jmr.v17i34.83}

يمنح الحلم المنامي الحقيقي الإنسان ليعبر عن مكبوتاته في اللاوعي. إن الأحلام السردية هي محاولة تخفي

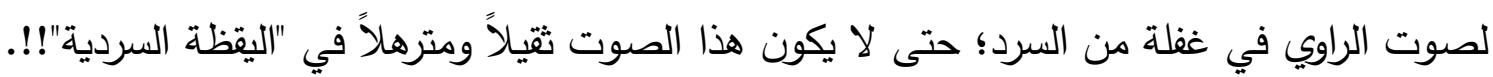
4-وظيفة لغوية: تتميز لغة مشاهد الرؤى والحلم السردي في النص أنها أكثر شعرية وشفافية من مشاهد

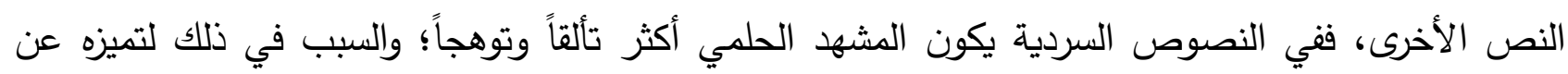
مشاهد السرد الأخرى، فضلاً عن ذلك كون الأحلام ذات طبيعة فائقة؛ فيعد السارد الى تلوين المشهر الحلمي

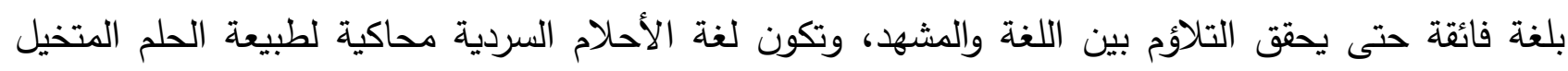

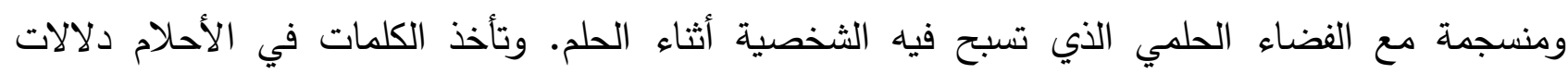
سيميائية ومرجعية لها علامات ثقافية ورموز تأويلية معينة، بحيث تعمل هذه اللغة الحلمية على بناء صورة لهاء محمولات تأويلية معينة. 5-بناء الصور : الأحلام السردية هي في الأصل "ثقافة صورة" يراد تثبيتها، ومن ثمَّ تأويلها؛ فتحقق الأحلام السردية مشهداً لصورة داخل النص؛ يمكن تأويل فضائها بكل تقاصيله؛ فزمان الحلم، ومكانه، وألوانه، ومركزه

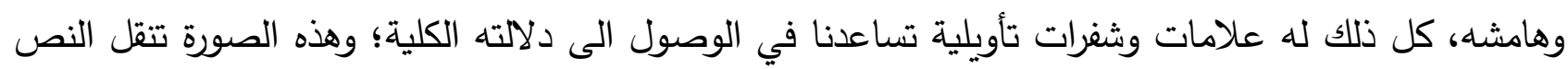

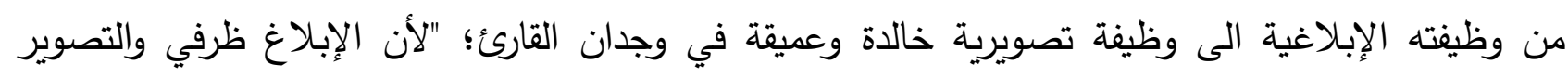

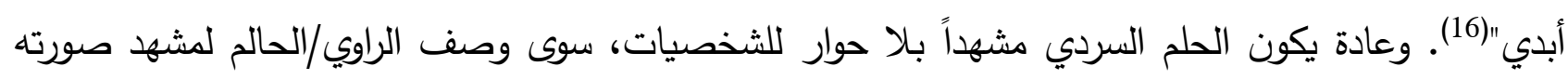

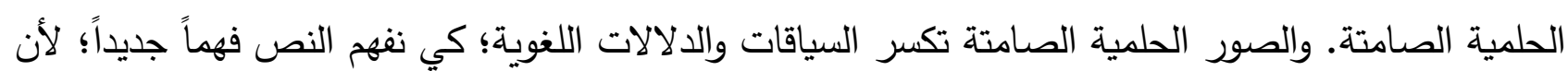
"بإمكان المرء أن يشاهد أي صورة دون حاجة الى لغة، ولا يحتاج الى سياقات ثثافية ولا فكرية كي يفهم

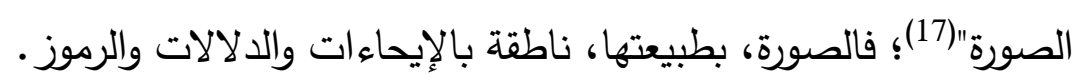

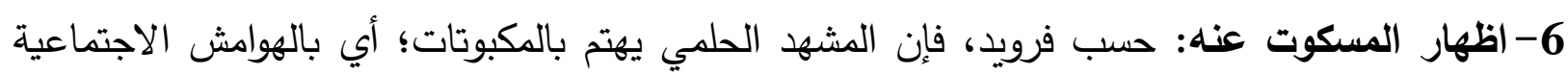

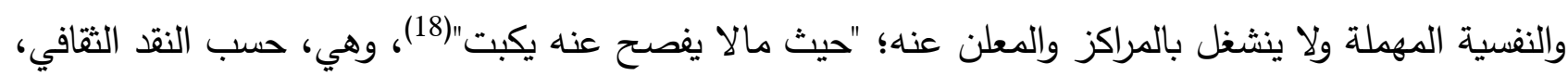

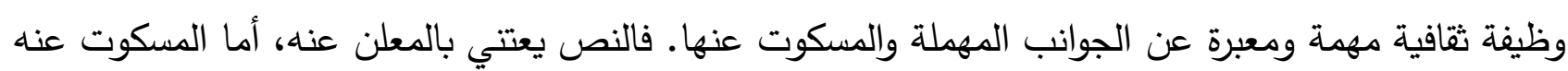
فتكثفه مشاهد الرؤى والأحلام. 7- الوظيفة الثكلية: الأحلام لها علاقة بالأشكال، والألوان، والأسماء، والثخصيات الرمزية، والأماكن

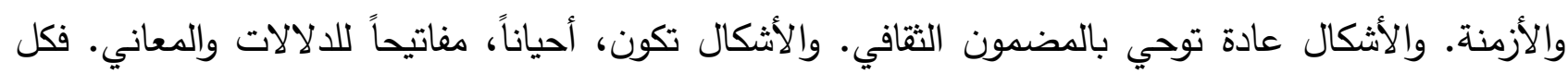

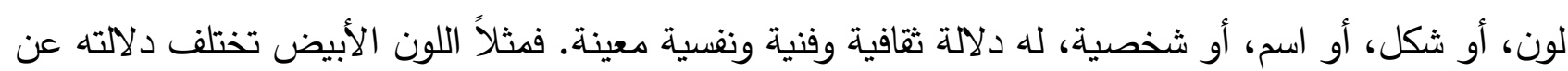




\section{هبلة أبحاث هيسان، المبلد السابع عشر، العدد الرابع والثلاثون، كانون الأول، السنة 2021 \\ https://doi.org/10.52834/jmr.v17i34.83}

اللون الأسود، و"الأفعى" في الرؤيا تختلف دلالتها عن "الطير"، مثلاً. وشخصية رمزية دينية معينة تختلف عن شخصية مخادعة وشيطانية؛ وهكذا تكتسب تلك الاشكال والألوان والأسماء والثخصيات وظائف شكلية معينة.

\section{الوظائف النفسية}

حسب الرؤية النفسية فإن الأدب نتاج النفس. لهذا تعمل الأحلام السردية على تكوين شبكة علاقات واسعة من العلامات الثقافية، التي تسهم الى حد كبير في تثكيل الوظائف والدلالات في النص. تفتح مشاهد الأحلام

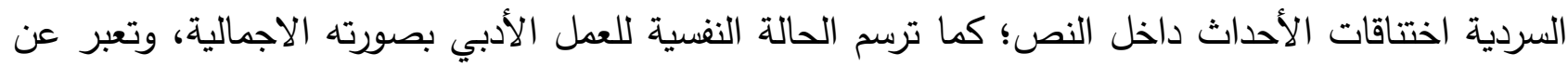

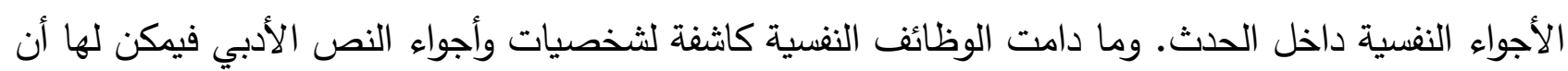
تدخل ضمن الوظائف الفنية في العمل الأدبي؛ لكن تم فرزها لضرورات بحثية الضئ.

\section{تحقق الأحلام السردية الوظائف النفسية الآتية:}

1-كثف الأت: تحقق الأحلام السردية كثفاً للذات والتعبير عن الحالات النفسية لثخصيات العمل

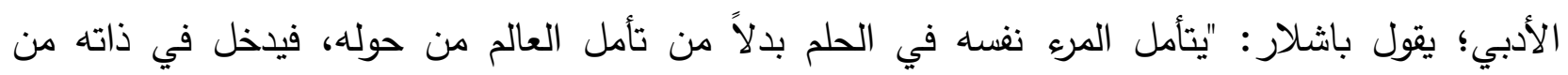

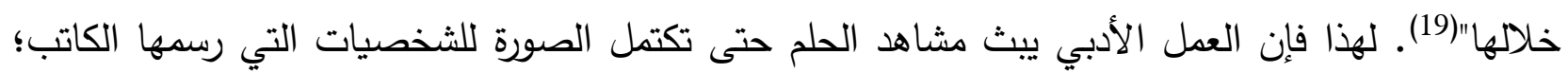
كذلك يتم إزالة الضبابية عن الحدث وغموض شخصياته في مشاهد الأحلام. في الواقع يمكن للشخصيات أن الن الثان

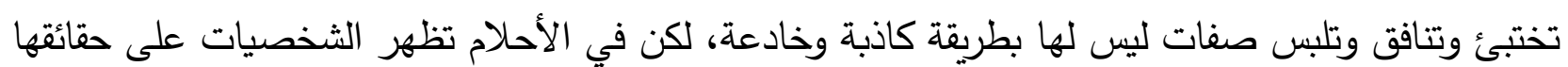
المسكوت عنها في عالم اليقظة.

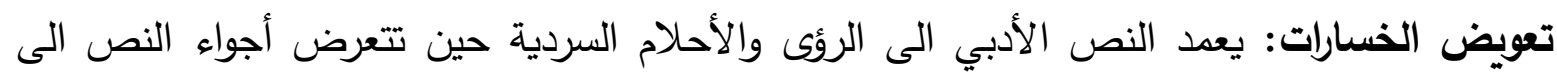

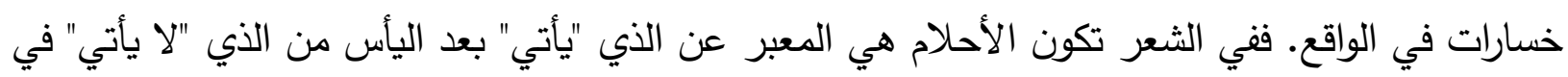
الواقع الذي يرسمه النص الثعري. أما في الرواية، فتكون الأحلام "تصراً خيالياً" على تلك الخسارات المؤلمة التي تتعرض لها الثخصيات

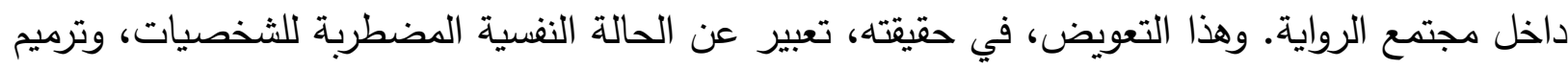

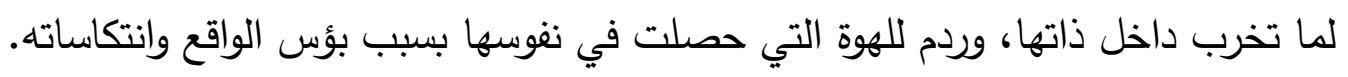

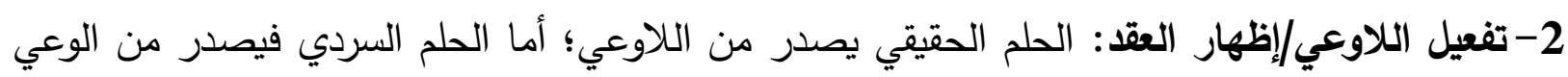
للتعبير عن اللاوعي السردي. فاللاوعي هو الذي يكثف عن المناطق المجهولة في يقظة الحياة. وما يكرهه الناس بثدة في الحياة يتحول الى مجموعة "عقد" في نفوسهم؛ وهذه العقد تظهر في أحلامهم على شكل كوابيس ومشاهد مفزعة تطابق الحالة النفسية التي يعانون منها في الواقع الضاغط علئ فئهم. 


\section{هبلة أبحاث هيسان، المبلد السابع عشر، العدد الرابع والثلاثون، كانون الأول، السنة 2021 \\ https://doi.org/10.52834/jmr.v17i34.83}

أما في الأدب فإن الأحلام السردية هي من تؤدي وظيفة البوح عن العقد والمكبوتات للشخصيات

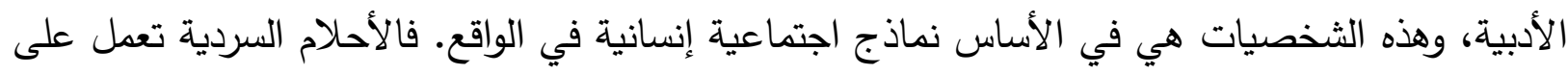

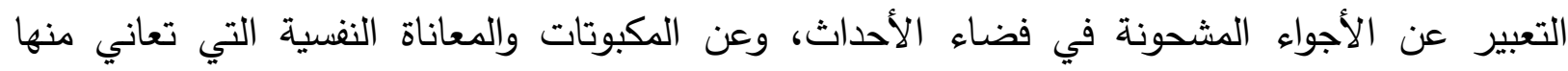

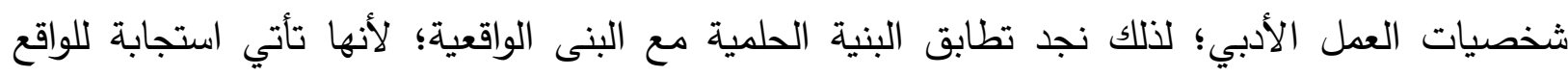

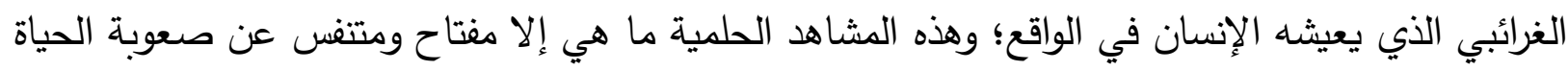

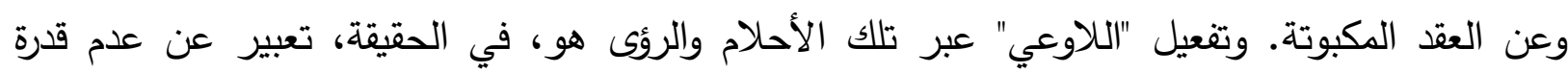
"الوعي" على التأقلم والتكيف مع الواقع الاجتماعي الضاغطيل.

في الحقيقة، إن الثعوب لها نشاطان: عقلي ينتج العلوم والأدب والفلسفة، ونثاط رمزي يصنع المتخيلات، وينتج الرموز والطقوس والثعائر • والنشاط الرمزي حاجة ضرورية لهذه المجتمعات، مثله مثل الإنجازات العقلية

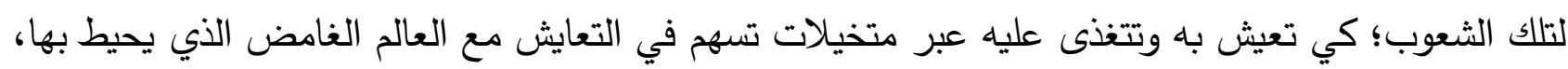

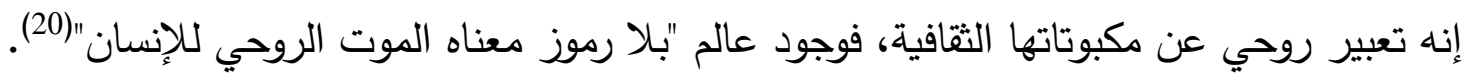

وهنا تكون وظيفة "الدين السماوي" اشباع تلك الحاجات الروحية والرمزية للإنسان، بطريقة منظمة ومفيدة

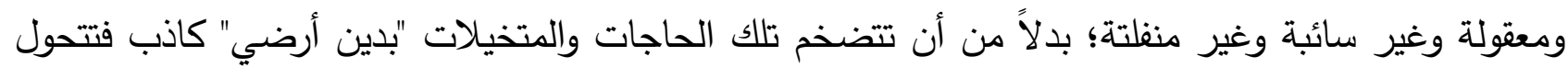
ممارساته الروحية والرمزية الى طقوس تسهم في تخلف الإنسان وتؤسس ذهنه على اللامعقول وعلى الخرافة. 


\section{هبلة أبحاث هيسان، المبلد السابع عشر، العدد الرابع والثلاثون، كانون الأول، السنة 2021 \\ https://doi.org/10.52834/jmr.v17i34.83}

تكون الرؤى والأحلام جزء من تراث الإنسان الرمزي والتخييلي؛ لذلك تقوم بوظائف كثيرة في عالم يحكمه

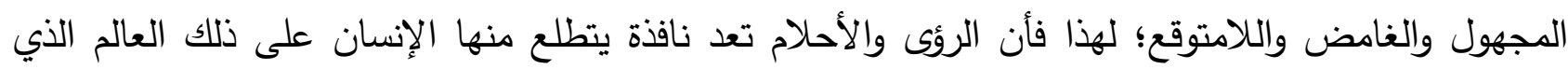
يحيط به. فالعلم وحده لا يمكنه السيطرة على ظواهر دينية ونفسية واجتماعية تحكم الإنسان وتتحكم به.

ويرى الباحث "سمر الديوب" بأن الرؤيا نوعان: تنبؤية مستقبلية، وانكفائية ماضوية. فضلاً عن ذلك فإن

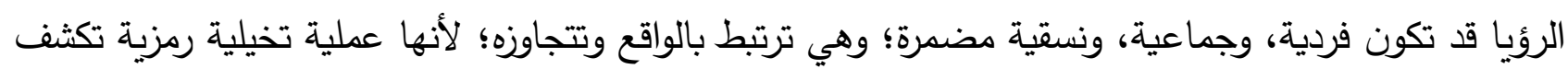

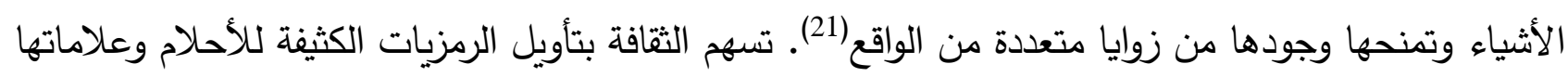
السيميائية؛ فتعبير الأحلام "تأسست على مرتكزات عدة مستمدة من سياقات دينية ولغوية وعرفية"(22).

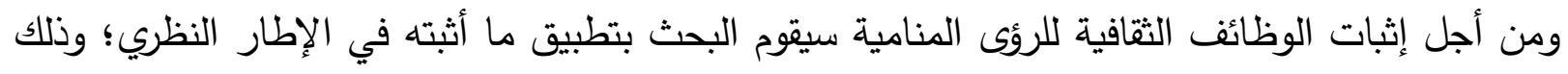

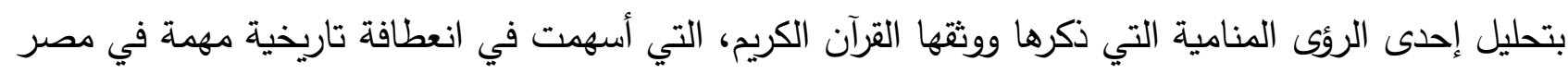

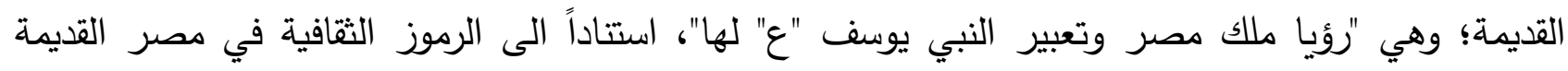

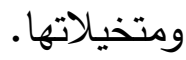

\section{رويا ملك مصر: البقرة الرمز الثقافي الديني}

في مصر القديمة، وفي مرحلة المجتمع الزراعي الذي مرت به البشرية، تأخذ "البقرة" رمزاً ثقافياً ودينياً

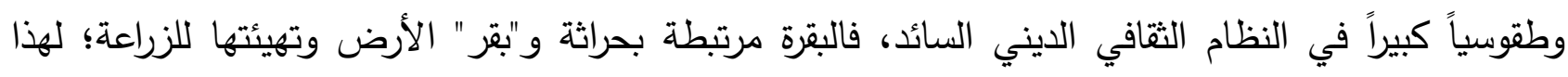

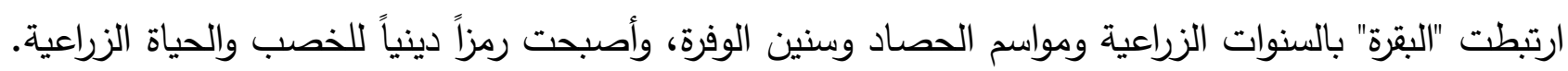
وكانت "عشتار" في العبادة الوثنية الأرضية هي "الأم الكبرى" التي لا أحد قبلها فهي التي خلقت وأعطت (23).

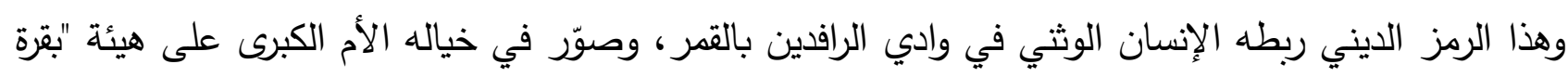

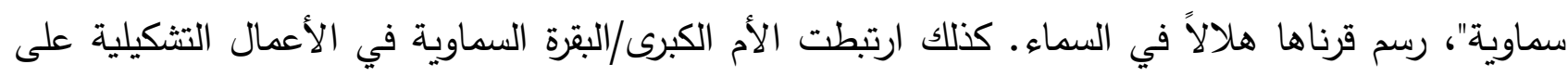

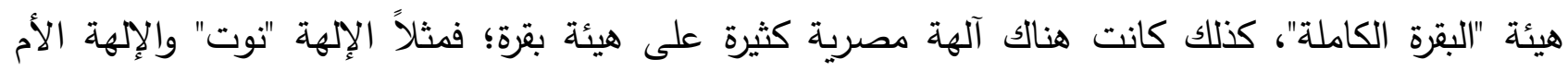
"نيت"، المصريتان كانتا تصوران على هيئة بقرة كاملة (24). 


\section{هبلة أبحاث هيسان، المبلد السابع عشر، العدد الرابع والثلاثون، كانون الأول، السنة 2021 \\ https://doi.org/10.52834/jmr.v17i34.83}

استتاداً الى ذلك كله، كانت "البقرة" ذات دلالة دينية رمزية طقسية في نفسية الجماعات البشرية المصرية؛ لهذا كان هذا الرمز هو "السبب التقافي" في رؤيا ملك مصر "سبع بقرات وسبع سنبلات" التي يذكرها القرآن

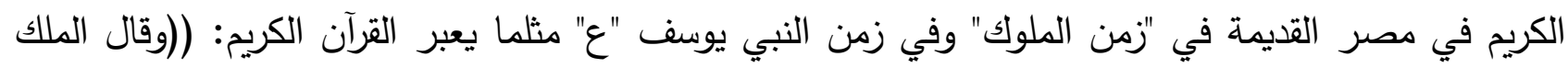

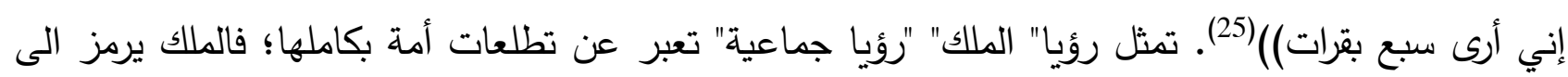
التمثيل الجمعي للناس، بوصفه رأس الهرم ومنظومة الحكم. و"رؤيا السبع بقرات" انتجت ولتبات واقعاً جديداً في الحياة

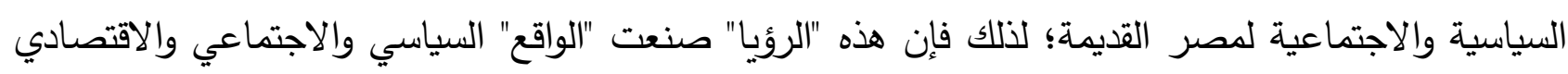
وشكلته من جديد؛ ورسمت مستقبل بلد بأكمله، وتحكمت في مصائر جماعات بشرية كبيرة.

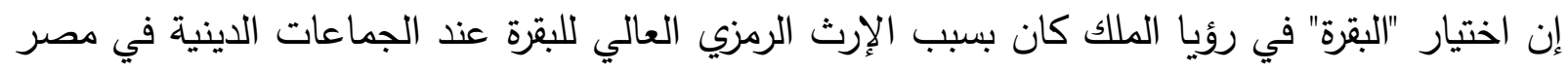

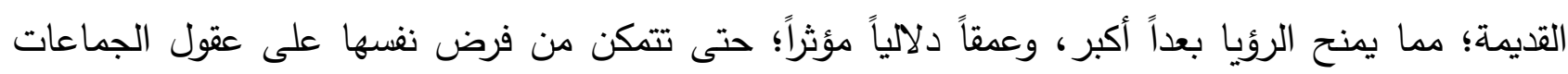

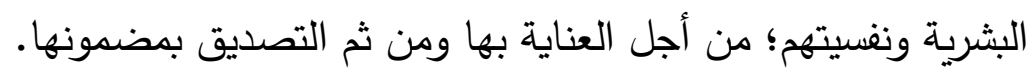

وبوساطة هذا الإرث الرمزي الثقافي الديني "للبقرة"، تمكن النبي يوسف "ع" من تفسير تلك الرؤيا المعروفة، وتأويل رموزها بأنها "سنوات" الوفرة والقحط الزراعي، وتمكن من تمرير خطابه النبوي ورسالته السماوية من خلال

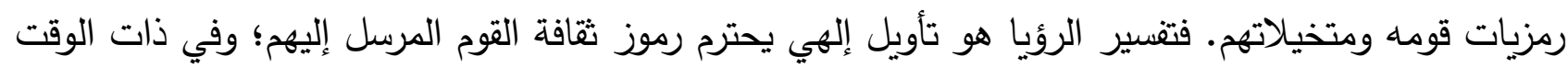

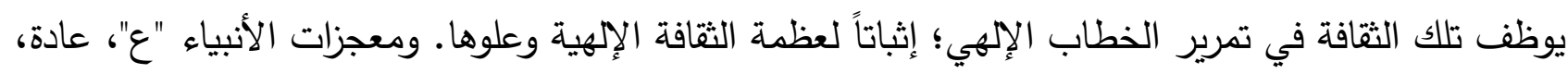

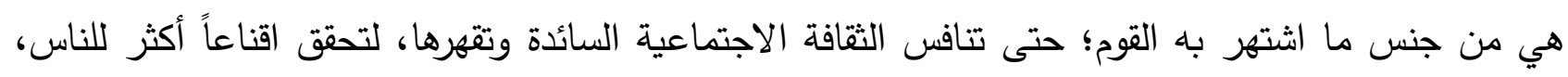
وقدرة أكثر على تثبيت مفاهيمها في نفوسهم، فضلاً عن التحدي الكبير لتلك الثقافة والسيطرة عليها. والرموز الثقافية الدينية لا تتجمد دلالاتها الثقافية؛ بل تتحرك وتتراكم عليها علامات سيميائية جديدة عبر التافي

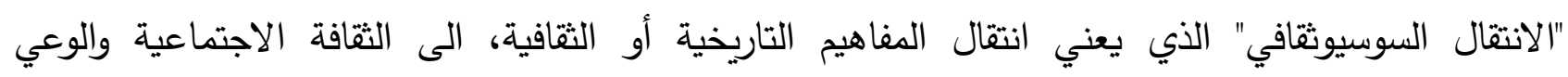

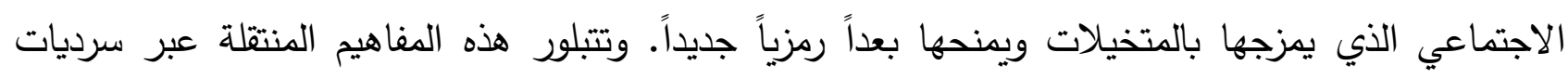

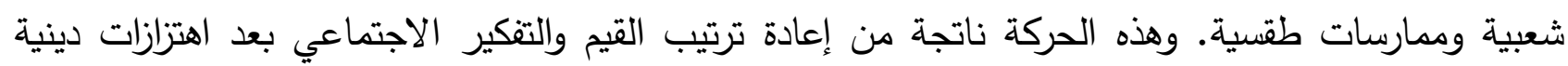

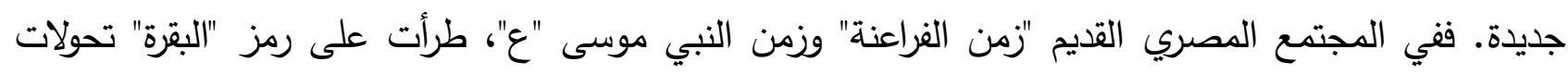

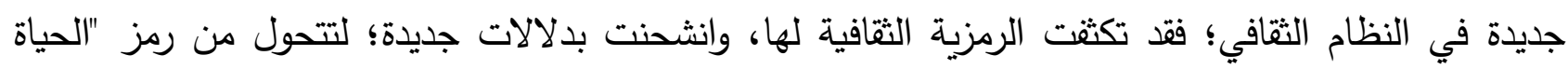

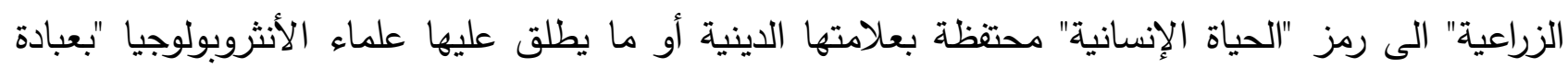




\section{هبلة أبحاث هيسان، المبلد السابع عشر، العدد الرابع والثلاثون، كانون الأول، السنة 2021 \\ https://doi.org/10.52834/jmr.v17i34.83}

الطوطم"(26). فقد عبد بني إسرائيل "العجل" في زمن النبي موسى ع؛ وهذه العبادة الحيوانية تجعلنا ندرك البنية الدينية والثقافية والرمزية "للبقر".

والثقافة "الطقسية للبقرة" عند الجماعات البشرية هي التي تجعلها تنساب عبر طبقات التاريخ وتعيش في

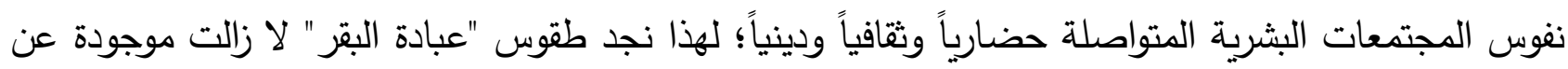

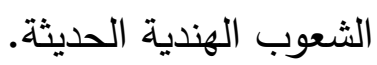

وتلك الأسباب الثقافية والدينية والطقسية المتجذرة في لا وعي الناس التي رافقت "البقرة" المقدسة في الثقافة

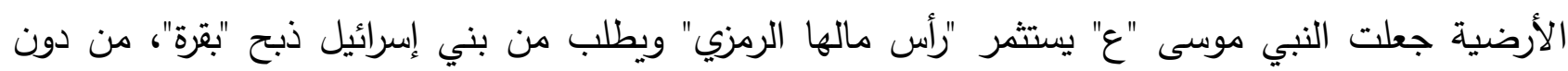

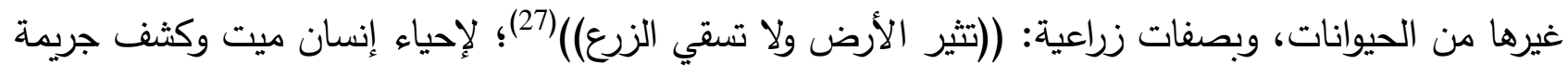

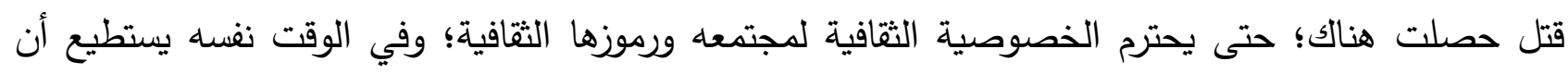

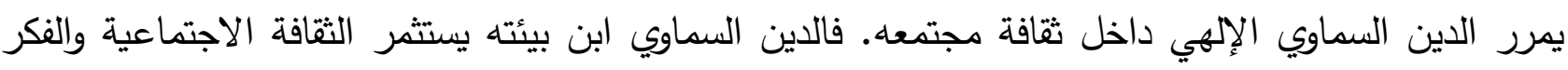

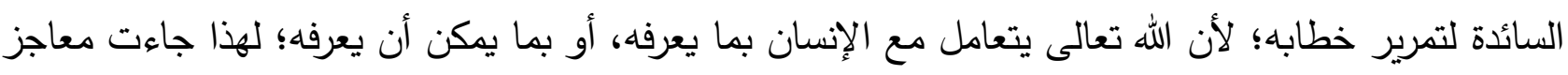

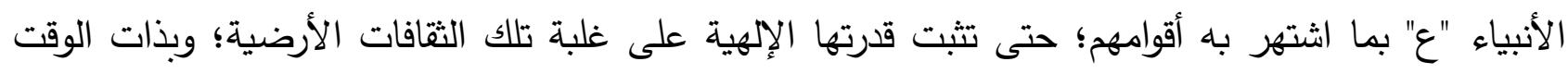

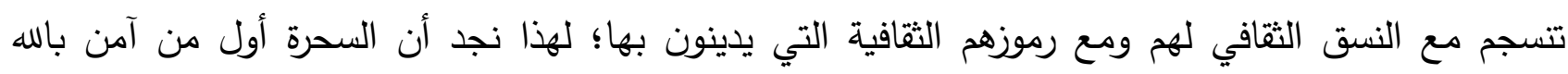

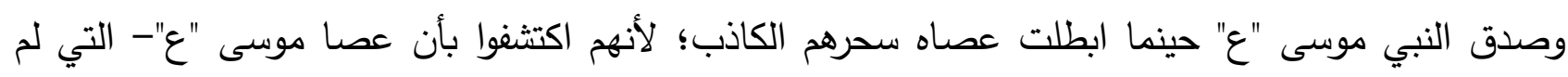

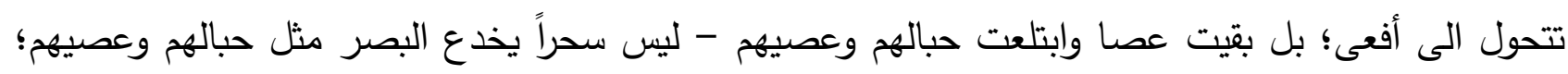

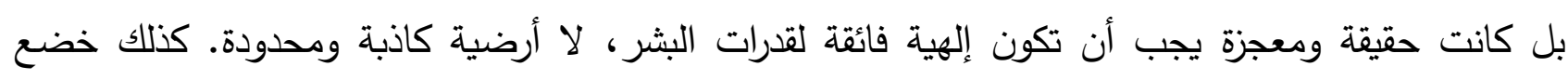

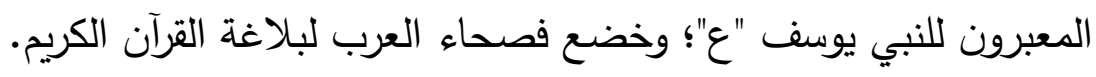

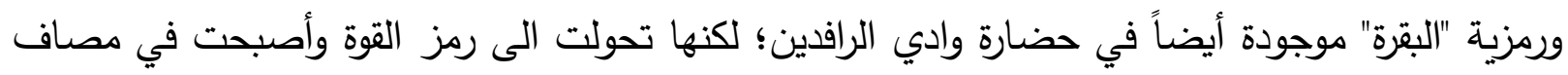
الآلهة العراقية الكثيرة؛ نجد ذلك واضحاً في الرسومات وفي الأدب الرافديني؛ فالرسوم العراقية القديمة كان أكثرها

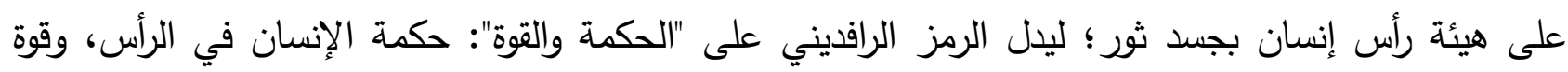

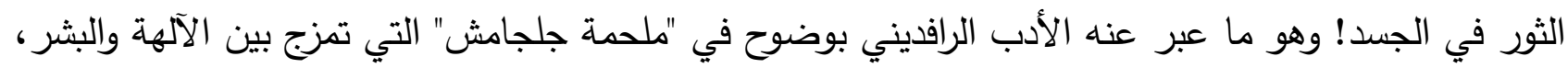

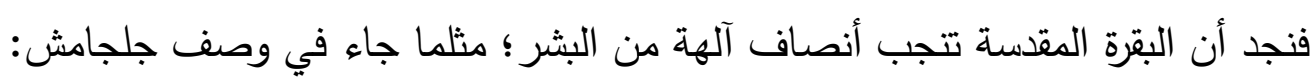

$$
\text { "إنه البطل، سليل أوروك والثور النطاح. ابن البقرة الجليلة (رمات - نُنسن). }
$$




\section{هبلة أبحاث هيسان، المبلد السابع عشر، العدد الرابع والثلاثون، كانون الأول، السنة 2021 \\ https://doi.org/10.52834/jmr.v17i34.83}

ثلثاه إله، وثلثه الآخر بشر، وهيئة جسمه مخيفة كالثور الوحشي"(28).

تأسيساً على ذلك كله، نجد العبادة السماوية تحترم الخصوصية الثقافية للأمم وتوظف ما اشتهر به القوم

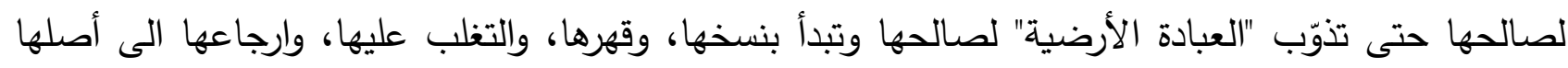
التوحيدي؛ لأن الديانات الأرضية الوثنية هي في حقيقتها تراكمات سوسيوثقافية وزيادات على الأصل التوحيدي. والديانات الأرضية المشوهة تصبح فيما بعد مصدراً للأساطير ؛ فالأساطير، في حقيقتها، ذات الات منشأ ديني، مثلما

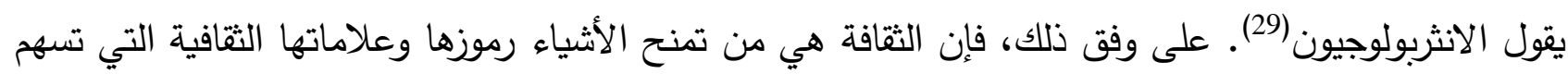

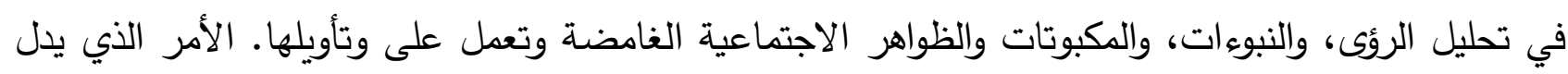

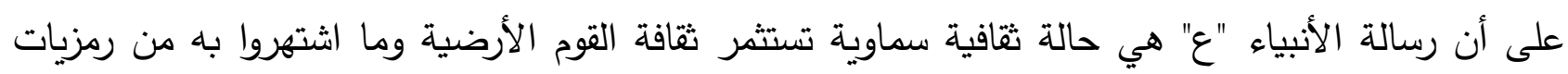

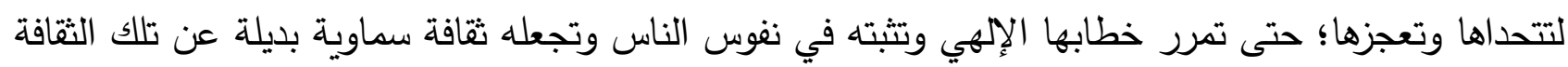
الأرضية ومتخيلاتها المخترعة.

في المستوى السردي/الفني، تحقق رؤيا ملك مصر "نسقاً عنقودياً سباعياً. إذ تتكون رؤيا ملك مصر من: "سبع بقرات سمان، وسبع بقرات ضعاف، وسبع سنبلات خضر ، وسبع سنبلات يابسة". ثم يأتي تعبير الرؤيا بنسق سردي سباعي أيضاً: "سبع سنوات زراعة وفيرة، وسبع سنوات قحط. ومن أجل دفع سنوات القحط يتم بناء

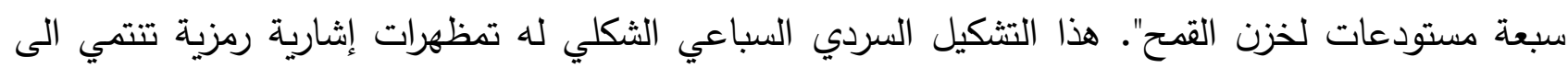

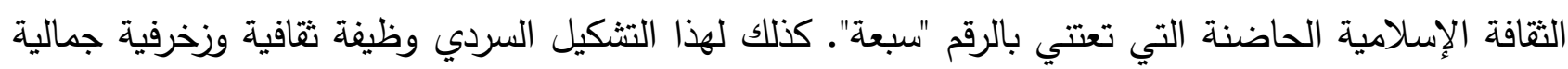
في آن واحد؛ وهو ما يساعد في شحن المعنى بإشارات تزيد من تماسك السرد وشده الى خيط قصصي والى الىدة؛

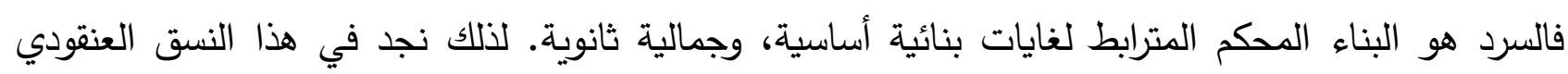
السباعي وظيفة بنائية جمالية في تتمية الحدث وتطويره من أجل الإمتاع والإثارة.

$$
\text { ثانياً: الأحلام السردية في الأدب }
$$

لا تخلو الأعمال الأدبية الكبيرة من الأحلام؛ إذ تتضمن تلك الأعمال أحلاماً، إما بطريقة مباشرة أو غير

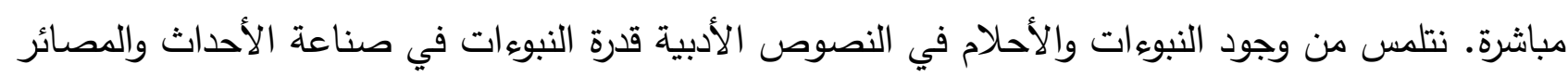
ومستقبل الأمم؛ فحتى الأدب العالمي تحدث عن قدرة النبوءات في التحكم في مصير الأمم والملوك؛ ولا سيما 


\section{هبلة أبحاث هيسان، المبلد السابع عشر، العدد الرابع والثلاثون، كانون الأول، السنة 2021 \\ https://doi.org/10.52834/jmr.v17i34.83}

مسرحية "أوديب ملكاً" للكاتب اليوناني القديم "سوفكليس" في عام (429 ق.م). كذلك نجد الأحلام في الملاحم مثل ملحمة جلجامش وإلياذة هوميروس والأوديسة.

وفي الثقافة الإسلامية، تعد الأخبار النبوئية في سيرة ابن هشام التي تستشرف بعثة النبي الاكرم "ص" من

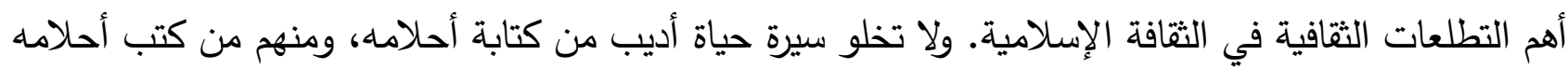

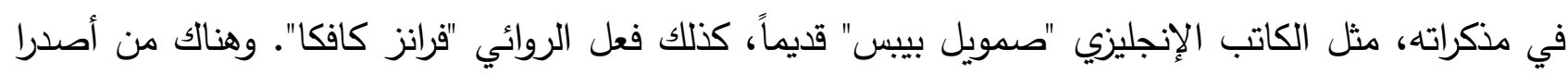

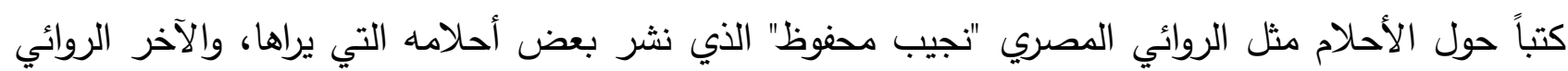

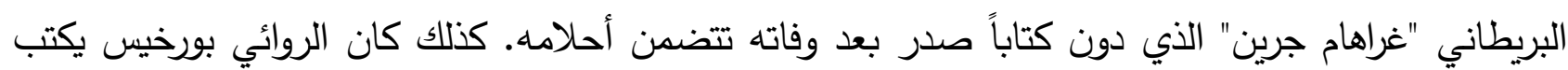

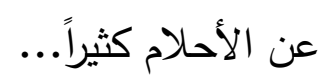

سيتناول البحث عينة من النماذج التي ظهرت فيها مشاهد الرؤى والأحلام السردية في متونها، وهي:

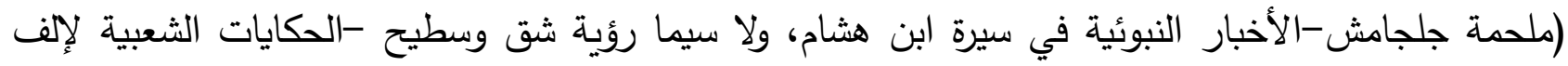

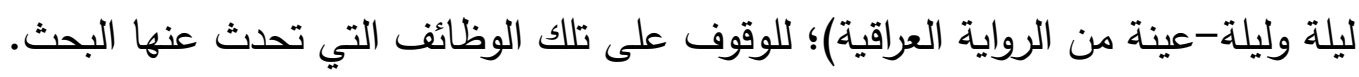

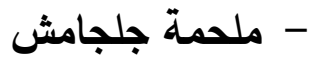

تعد ملحمة جلجامش "اققدم نوع من أدب الملاحم البطولية في تاريخ جميع الحضارات"(30)؛ تأخذ الأحلام

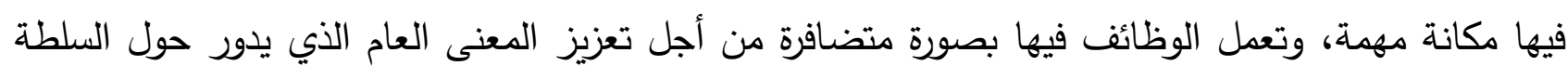
والموت والخلود في الحياة.

يأخذ مفهوم "الغيب" بعداً كبيراً في الملحمة؛ فقد كان جلجامش، حسب الملحمة الأسطورية يعلم الغيب

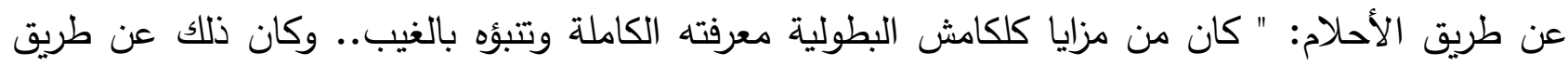

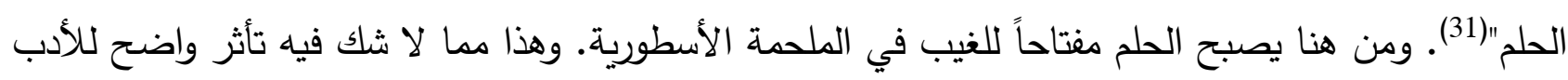

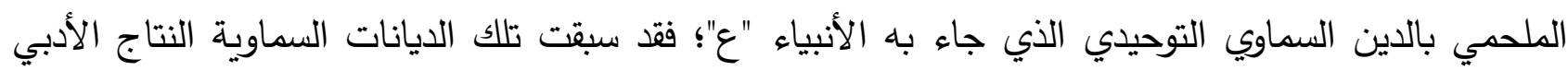
الأسطوري بالحديث عن موضوع الغيب والموت والخلود.

في نص الملحمة يرى جلجامش في منامه نجماً يهوي في الأرض؛ تفسره أمه بأنه صديقه أنكيدو: "استيقظ جلجامش في تلك اللحظة وأخذ يقص على أمه رؤياه قائلاً لها: 


\section{هجلة أبحاث هيسان، المبلد السابع عشر، العدد الرابع والثلاثون، كانون الأول، السنة 2021 \\ https://doi.org/10.52834/jmr.v17i34.83}

يا أمي لقد رأيت الليلة الماضية حلماً: رأيت أني أسير مختالا بين الأبطال فظهرت كواكب السماء، وقد سقط أحدها إليَّ وكأنه شهاب السماء "آنو"...

فأجابت جلجامش أمه البصيرة العارفة وقالت له:... - م

إنه صاحب قوي يعين الصديق سيأتي إليك ....

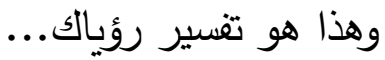

يا أمي رأيت رؤيا ثانية:...رأيت فأساً مطروحة...

قالت ننسون الحكيمة البصيرة لججامش: إن الفأس التي رأيت رجل"(32).

في هذين الرؤيتين نجد "انكيدو" مرة على هيئة "كوكب" والثانية على هيئة "فأس"، وهو تعبير يستند الى الى التئي

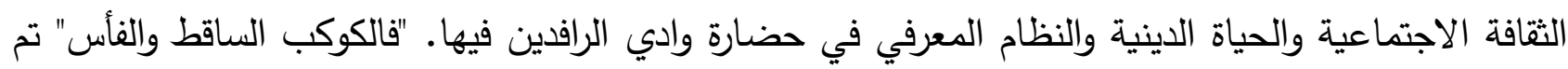

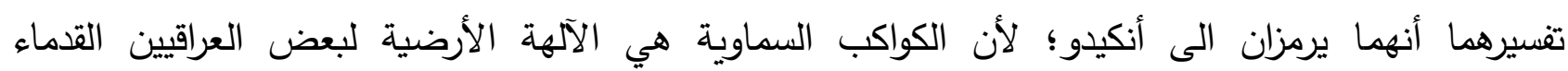

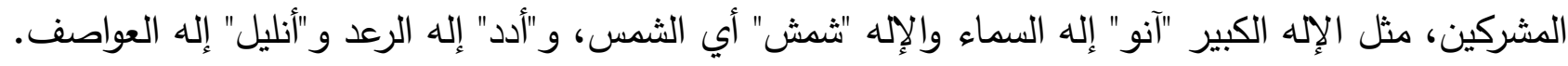

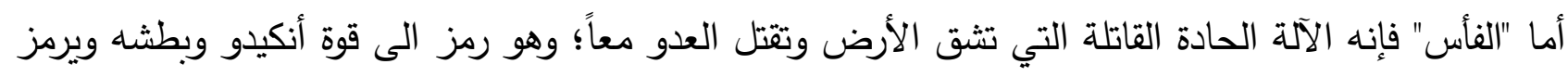

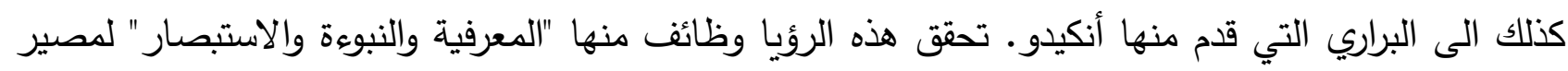

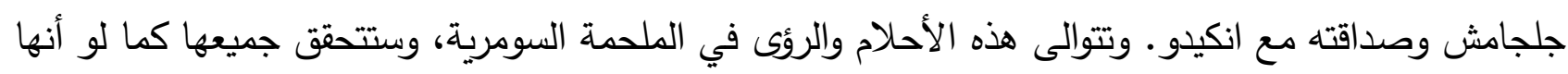

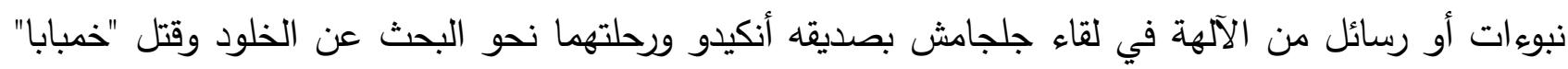
الكائن الأسطوري.

عملت الوظائف في هذا النص من ملحمة جلجامش بطريقة فعالة؛ فالوظائف النفسية عملت على كثف التف التفاء الذات، وتعويض الخسارات النفسية لجلجامش وتفعيل اللاوعي من أجل اللقاء بصديقه أنكيدو .

أما الوظائف الفنية فإننا نجد في هذا النص تداخل العوالم داخل الفضاء الحلمي، ونتلمس كذلك الوظيفة

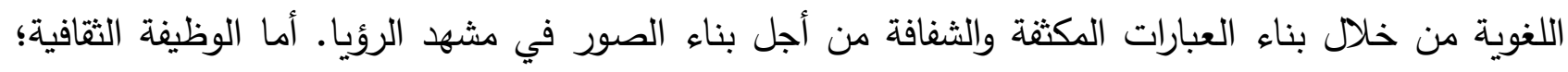

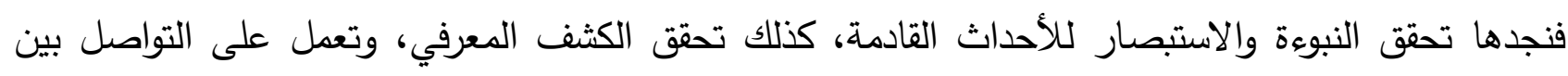

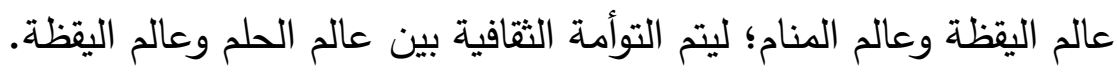




\section{هجلة أبحاث هيسان، المبلد السابع عشر، العدد الرابع والثلاثون، كانون الأول، السنة 2021 \\ https://doi.org/10.52834/jmr.v17i34.83}

- سيرة ابن هشام

سيرة ابن هشام دونها محمد بن إسحاق المطلبي (ت: 152 هـ)، وهي من أشهر البِيَر التي أُلْت في

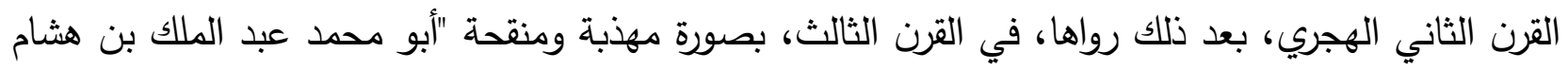

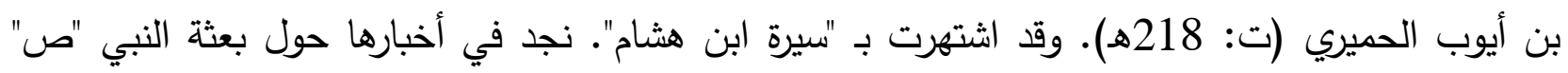

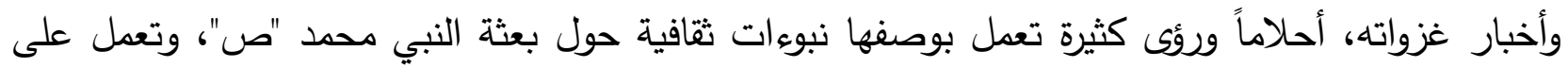
وظيفة مركزية هي الوسيط الثقافي بين ثقافة جاهلية وثقافة إسلامية قادمة.

ومن أهم الاخبار النبوئية في متن سيرة ابن هشام هي "رؤيا ملك اليمن ربيعة بن نصر وتأويل شق وسطيح

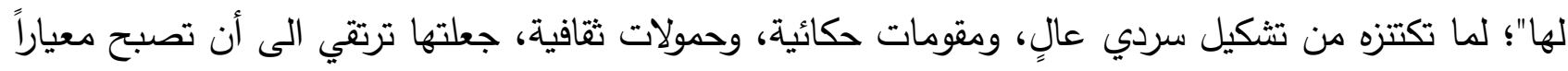

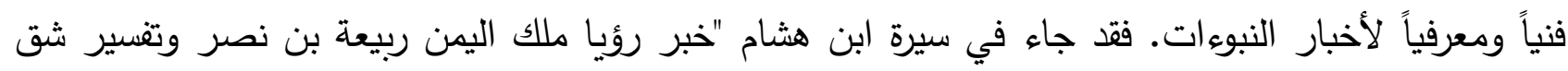

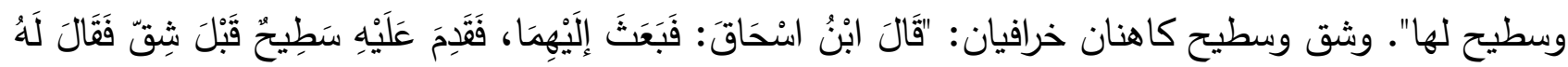

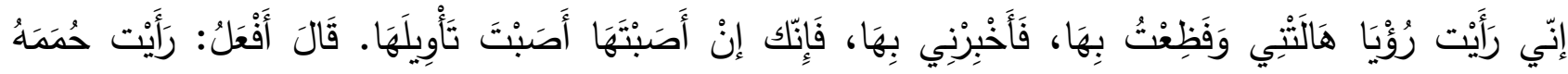

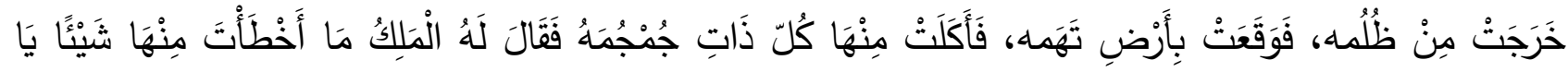

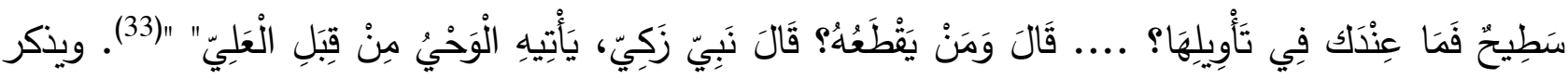

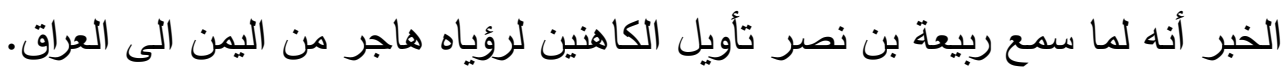

عملت هذه الرؤيا بصورة مركزية على وظيفة النبووة ببعثة النبي الاكرم "ص" والتبشير لها. وهذا الحضور

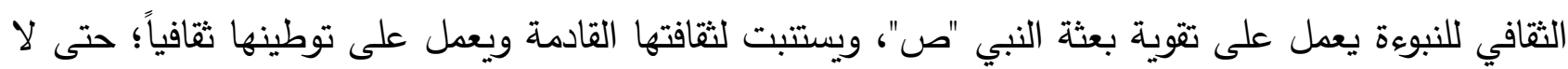
يتم تكنيبها أو استتكارها.

يوفر هذا الخبر النبوئي الوظائف التي تحدث عنها البحث من خلال تفعيل اللاوعي وتداخل العوالم وتحقيق

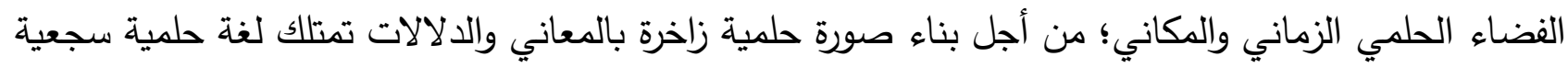
جميلة؛ فضلاً عن الوظيفة الثقافية المركزية وهي النبوءة والاستبصار للنبوة القادمة. 


\section{هجلة أبحاث هيسان، المبلد السابع عشر، العدد الرابع والثلاثون، كانون الأول، السنة 2021 \\ https://doi.org/10.52834/jmr.v17i34.83}

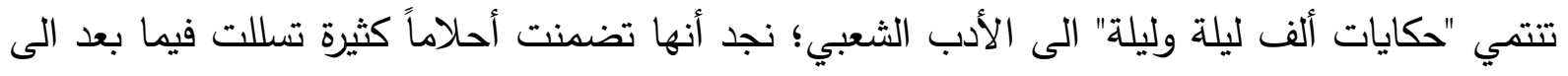
الآداب العالمية وأثرت فيها. مثل (حلم تاجر بغداد-حلم الأب صاحب البنات السبع -حكاية المتوكل مع محبوبة وحلمها-وحكاية جعر البرمكي والفوال-وحكاية الملك جليعاد والثماس)(34).

تحقق حكايات ألف ليلة وليلة الوظائف التي تحدث عنها البحث؛ إذ ينماز عالم الليالي بالسحر الخوارقي

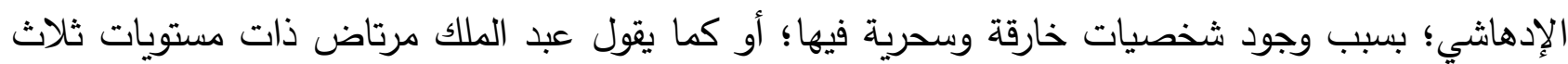

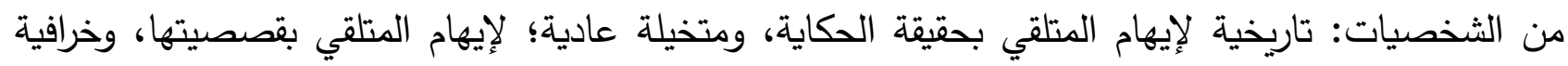
لإيهامه بأسطوريتها(35. ووجود هذه المستويات المتعددة من الثخصيات أكسب السرد طاقة كبيرة ومساحة واسعة ليحقق وظائف عدة، لاسيما الوظائف الفنية، مثل تداخل العوالم، وبناء الفضاء الحلمي، وبناء صنداء صور

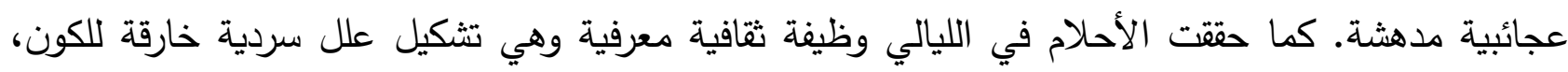

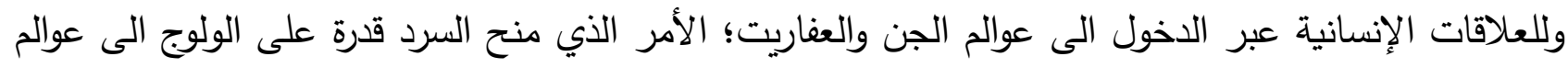
جديدة ومبتكرة وغير مأهولة.

والأحلام في الليالي، واستناداً الى وظائفها المذكورة، توفر مساحة واسعة للفنتازيا والسحر اللذان قامت عليه البنية السردية لتلك الحكايات الثعبية؛ وبالنتيجة تعمل الوظائف للأحلام السردية بصورة كبيرة داخل الحكايات من أجل تعميق ثيمة الحكايات وبنائها السردي.

*** $*$

\section{حضور الأحلام السردية في الرواية العرقية}

تقسم الروايات من حيث حضور الأحلام السردية في متتها الى "روايات حلمية" و"روايات غير حلمية".

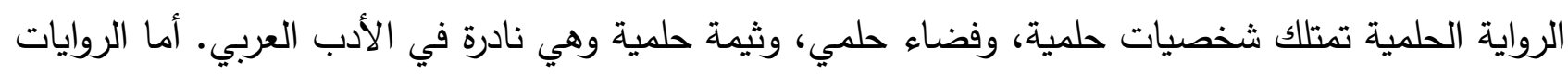
غير الحلمية فهي توظف الحلم في بعض مشاهدها لضرورات فنية ونفسية؛ فتعمل مشاهد الأحلام في المتن فئن

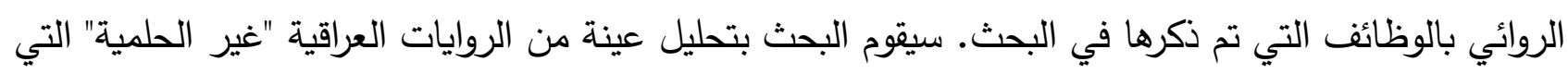
توظف بعض مشاهد الأحلام في أحداثها؛ لوضع اليد على وظائف الأحلام السردية في متونها. 


\section{هبلة أبحاث هيسان، المبلد السابع عشر، العدد الرابع والثلاثون، كانون الأول، السنة 2021 \\ https://doi.org/10.52834/jmr.v17i34.83}

في رواية "النظلة والجيران"(36)، للروائي غائب طعمة فرمان تعمل مشاهد الأحلام السردية على الوظيف

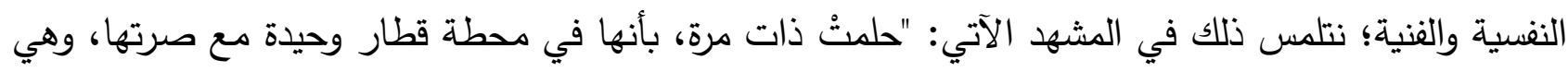

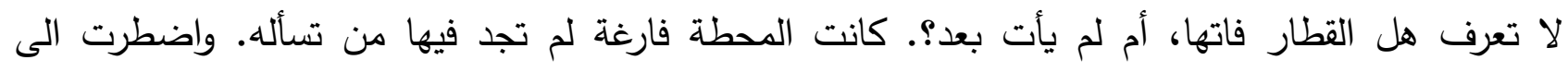

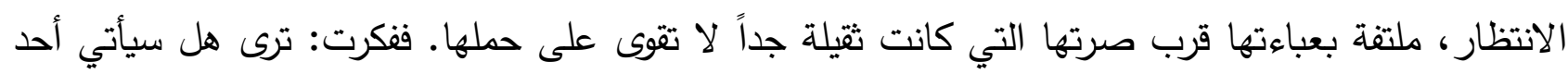

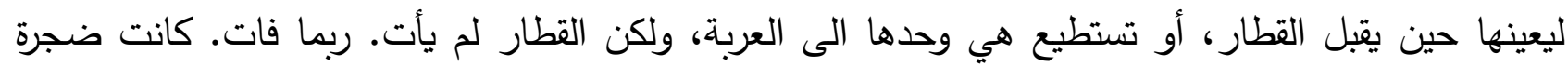
وخائفة" (37).

لا يحتاج هذا المشهد الحلمي الى كثير عناء لكثفه وتفسيره؛ فهو واضح المعالم. فالحالمة هي شخصية

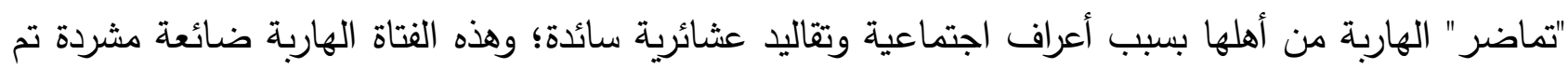

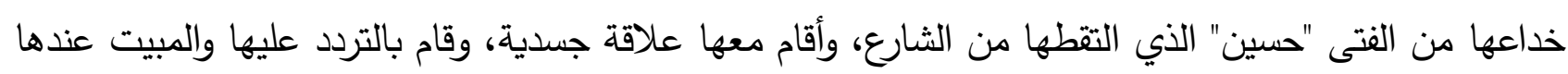
في غرفة أجّرها لها في أحد البيوت البغدادية البائسة؛ وأدركت فيما بعد بأنه خدعها ولا يستطيع أن يتزوجها.

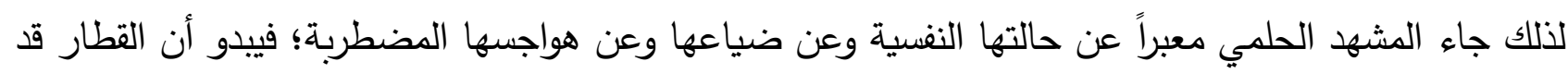

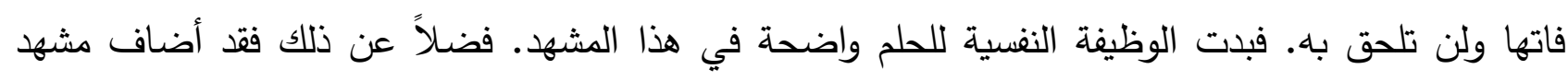
الحلم للسرد متعة أكثر ومنح القارئ فسحة جديدة للتأمل، وصرح بالالالات والمعاني التي تكثف لفي عن شخصيات

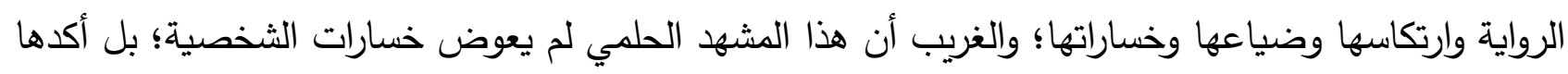

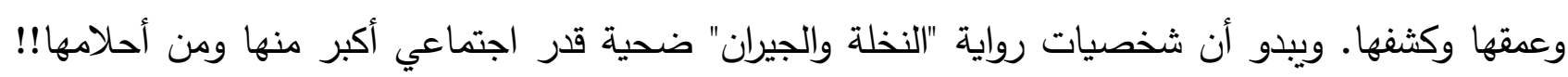

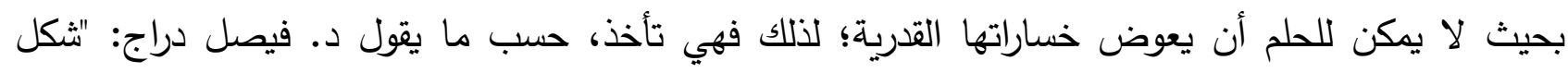

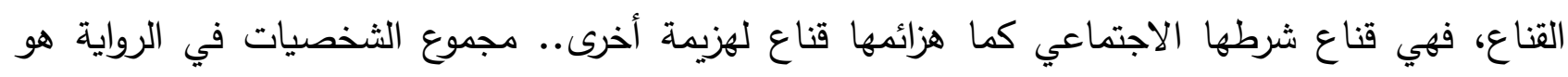
النموذج الاجتماعي الذي يشير الى شرط اجتماعي محدد...فالنموذج لا يحيل الى أفراد؛ بل الى قوى اجتماعية تتجاوز الأفراد"(38).

فثخصيات "النخلة"، على وفق ذلك، هي شخصيات منهزمة هي وأحلامها أمام قوة القدر الضاغط، لأنها

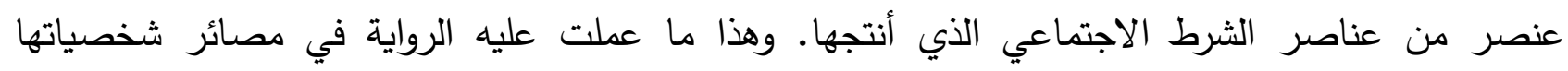
وانسحاقهم أمام أقدارهم وشروطهم الاجتماعية القاهرة. 


\section{هبلة أبحاث هيسان، المبلد السابع عشر، العدد الرابع والثلاثون، كانون الأول، السنة 2021 \\ https://doi.org/10.52834/jmr.v17i34.83}

أما في رواية "الرجع البعيد"(39) للروائي فؤاد التكرلي، فتتشر بعض المشاهد الحلمية انسجاماً مع البناء

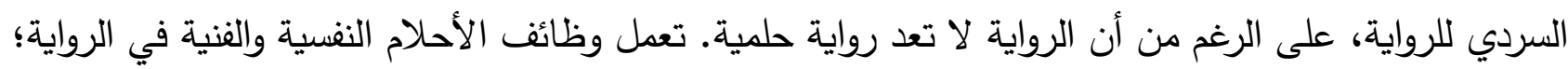

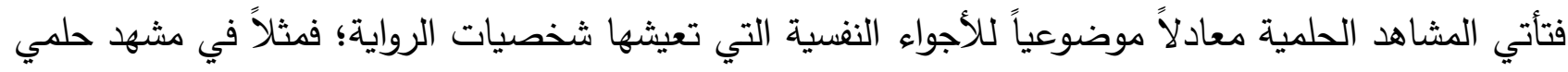
في هذه الرواية للشخصية "عبد الكريم" الذي شهد حادث موت صديقه "فؤاد" تحت عجلات السيارة؛ وكان هو

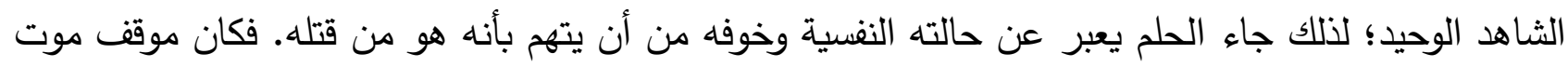

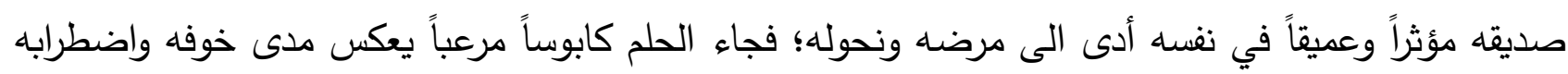

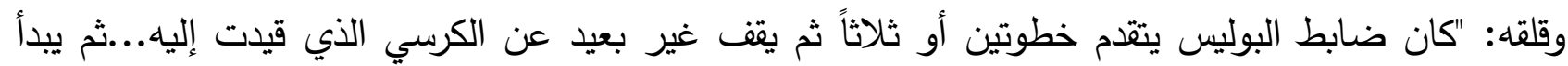

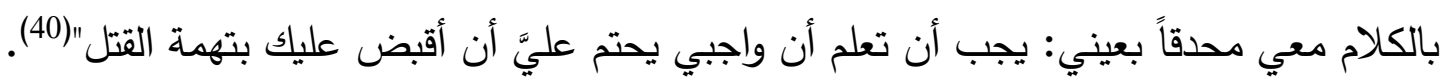

في هذا النص تعمل "الوظيفة النفسية" في كثف الذات وهواجسها من خلال تنعيل اللاوعي في الثخصية؛

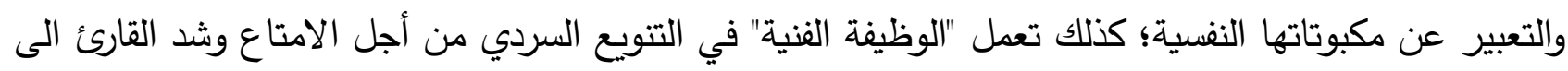
السرد، من خلال بناء صورة حلمية كاشفة عن اختلاجات الشخصية وهواجسها؛ وفي ذات تعمل على الثيل انسيابية

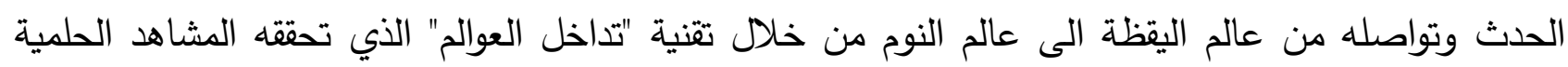

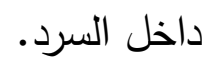

وفي رواية "سيدات زحل"(41) للروائية لطفية الدليمي؛ تكثف الأحلام عن وظيفة تجليات الذات وهي تتنقل

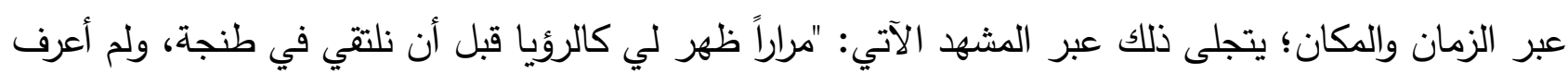

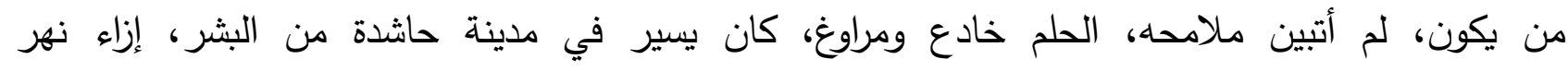

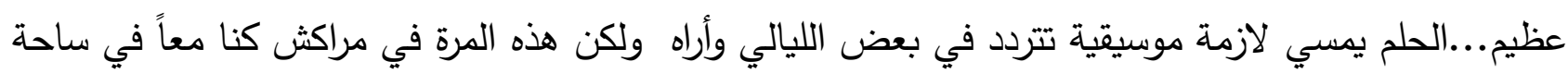

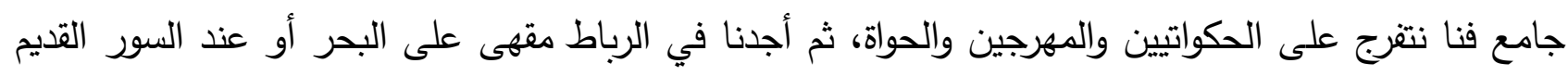
وسط السوق...وأجدني في حلم آخر في القاهرة"(42). 


\section{هبلة أبحاث هيسان، المبلد السابع عشر، العدد الرابع والثلاثون، كانون الأول، السنة 2021 \\ https://doi.org/10.52834/jmr.v17i34.83}

تعمل الوظائف الفنية لمشاهد الأحلام في الرواية أكثر من بقية الوظائف الأخرى؛ لأن الأحلام في الروايات

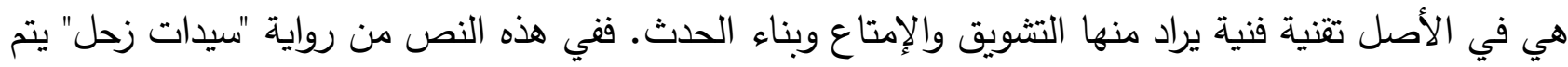

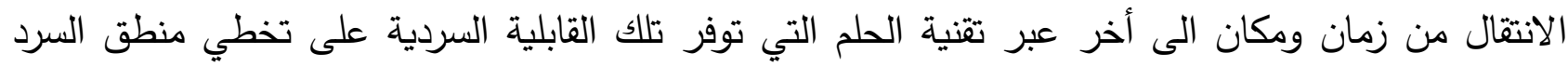

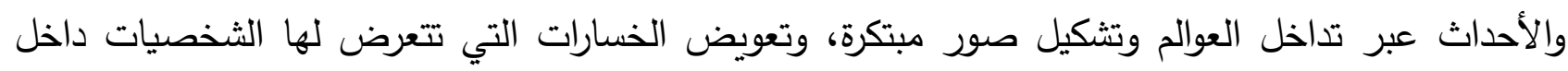

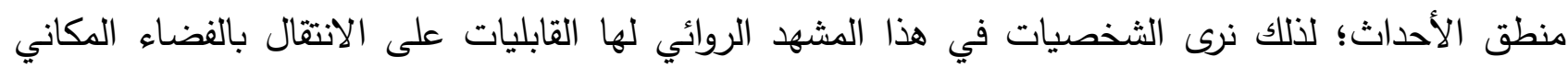
والزماني بما ينمي الأحداث والثخصيات وينعش الثيمة المركزية ويشبع تطلعات الثخصيات وخساراتها، واظهار المسكوت عنه في أعماقها.

أما في رواية "وحدها شجرة الرمان" للروائي سنان أنطون(43)، فنجد أن متنها يتكون من السرد الواقعي

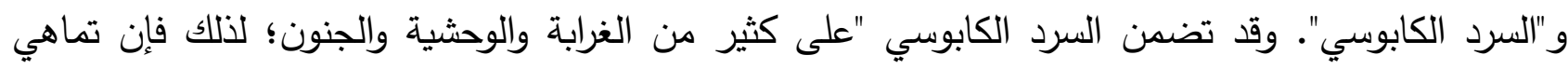

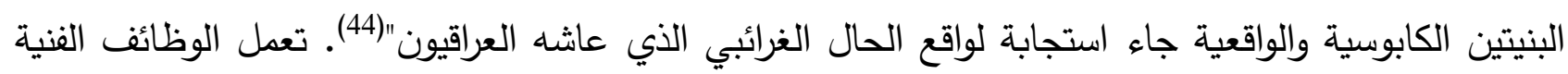

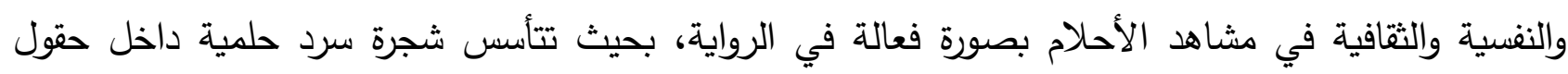

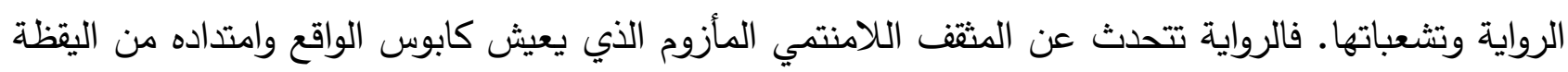
الى النوم. إن انزراع الكوابيس في النص أسهم هو الآخر في تكريس وحثة المثقف وغربته في وطنه (45).

يمكن تسجيل الوظائف النفسية لمشاهد الأحلام في هذه الرواية أكثر من غيرها من الوظائف الأخرى، وهي

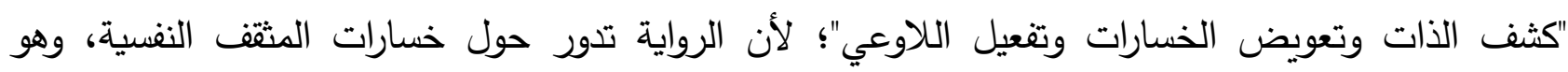

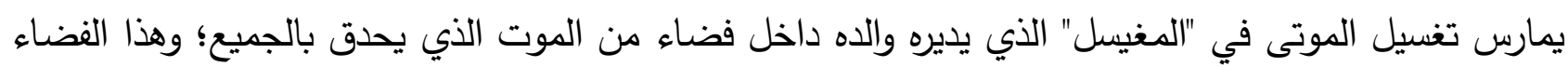
مدعاة للهروب من الواقع الى الأحلام والكوابيس. تعمل وظيفة "تعويض الخسارات" بصورة كبيرة ولافته في متن

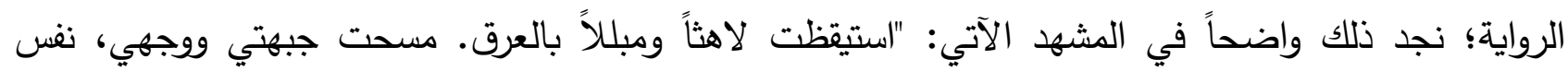
الكابوس يتكرر منذ أسابيع"(46). تثاهد الثخصية الرئيسة "جواد" صديقته "ريم" في منامات كثيرة ومتكررة: "بدأ لأل المطر يتساقط. أغضضت عينيها. مسحتُ قطرة عن أنفها بسبابتي. كانت بشرتها ساخنة مما يعني بأنها حية.

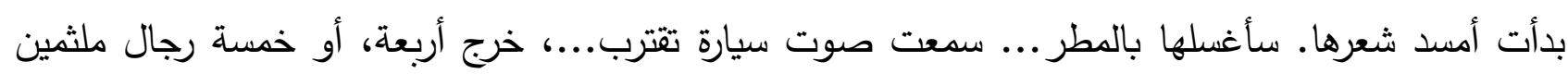




\section{هبلة أبحاث هيسان، المبلد السابع عشر، العدد الرابع والثلاثون، كانون الأول، السنة 2021 \\ https://doi.org/10.52834/jmr.v17i34.83}

يرتدون الخاكي، ويحملون رشاشات وركضوا باتجاهنا. حاولت أن أحميها بيدي اليمنى، لكن أحدهم كان قد

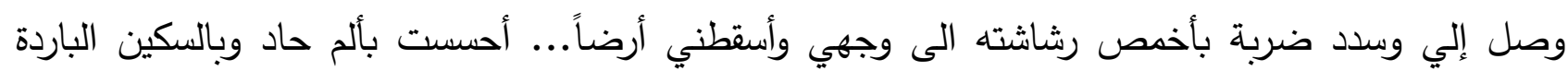
تخترق عنقي. سال الدم الحار على صدري وظهري. سقط رأسي على الأرض وتدحرج على الرمل ككرة"(47).

يبوح هذا الشهه الحلمي عن الأجواء الخانقة التي تعيثها الثخصية الرئيسة في الرواية ويعمل على وظيفة

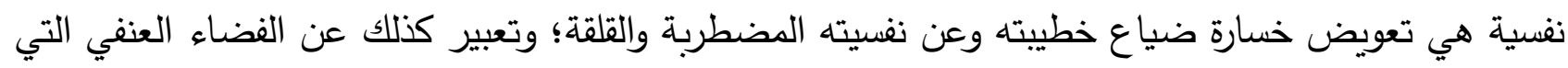

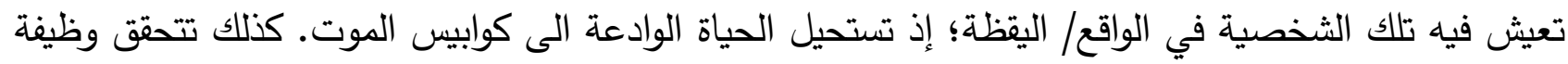

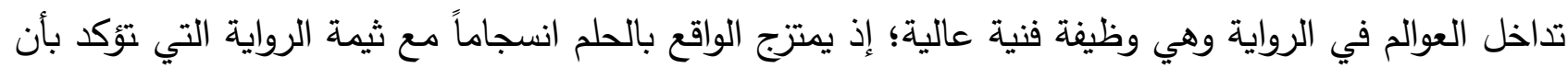

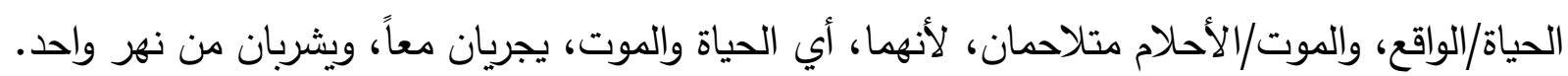

$* * *$

\section{نتائج البحث}

توصل البحث الى النتائج الآتية:

1- توصل البحث الى أن الرؤى والاحلام السردية لها مكانة كبيرة في نفسية الأمم وتطلعاتها المستقبلية؛ لذلك حضرت نللك الرؤى والاحلام في آدابهم وثقافتهم.

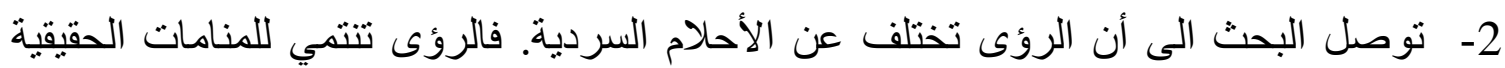

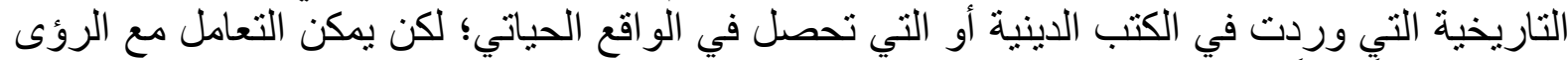

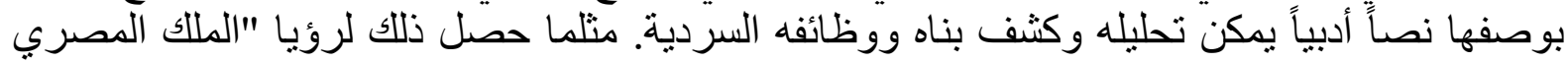

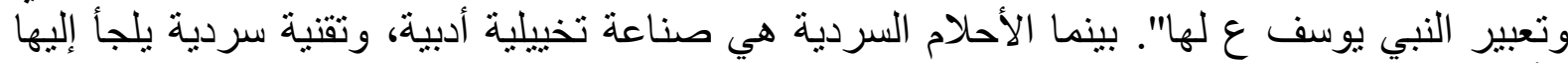
الأديب لغايات بنائية ووظائفية وجمالية.

3- توصل البحث الى أن الرؤى والأحلام السردية تثترك بثلاث وظائف كبيرة هي: الوظيفة

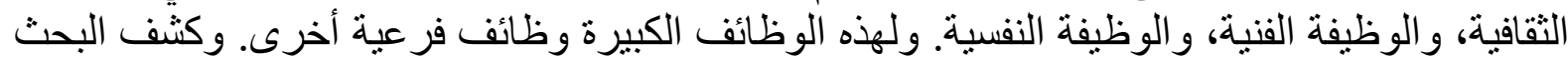
أن "الوظيفة الثقافية" أكثر حضور ال من بقية الوظائف الأخرى في الرؤى المنامية.

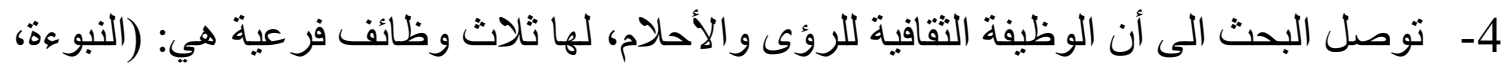
و المعرفة، والوسيط الثقافي). أما "الوظيفة الفنية" فلها سبع وظائف فرعية هي: (تداخل العو الم، تداخل 
الأزمنة، قناع الكاتب، وظيفة لغوية، بناء الصور، إظهار المسكوت عنه، الوظيفة الثكلية). أما "الوظيفة النفسية" فلها ثلاث وظائف فر عية هي: (كثف الذات، تعويض الخسار ات، تفعيل اللاوعي).

(1) - (1) ينظر : لسان العرب، مادة "رأى".

169 (2) 169

(3) (3ورة الصافات، آية 102 (3)

(4) سورة الإسراء، آية 60 (4) - (4)

. (5) - (5) سورة يوسف، آية

(6) ينظر : ست نزهات في غابة السرد، امبرتو إيكو: 191.

(7) (7) - (7الك المعنى، سعيد بنكراد: 74.

(8) لمزيد من الاطلاع ينظر : المنامات في الموروث الحكائي العربي، دراسة في النص الثقافي والبنية السردية، د. دعد الناصر : 45-58

(9) لمزيد من الاطلاع ينظر : شعرية الحلم في الرواية العربية: الأساليب، والبنيات والأنواع، أطروحة

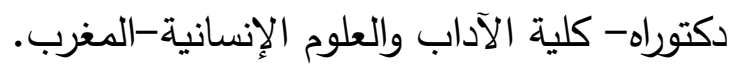

(10) السرد العربي القديم: الأنساق الثقافية وإثكاليات التأويل، د. ضياء الكعبي: 72. (11) ينظر : قواعد النقد الادبي، لاسل آبر كرومبي: 64 وما بعدها

(12) إثارة الى الحديث النبوي: ((الرؤيا الحسنة من الرجل الصالح جزء من ستة وأربعين جزء من النبوة))

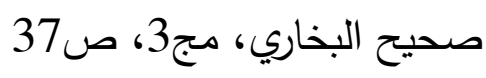

(31) نقد ثقافي أم نقد أدبي، عبد الغذامي-عبد النبي صطيف: 33. 


\section{هبلة أبحاث هيسان، المبلد السابع عشر، العدد الرابع والثلاثون، كانون الأول، السنة 2021 \\ https://doi.org/10.52834/jmr.v17i34.83}

(41) هو مثال بسيط أشار إليه فورستر في معرض حديثه عن الخيال الجامح. انظر : أركان الرواية، إ. م.

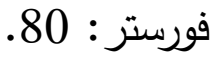

(15) ينظر : البناء الفني في الرواية العربية في العراق، ج3، د. شجاع العاني: 14

(16) نقص الصورة، "تأويل بلاغة الموت1"، ناظم عودة: 51

(17) الثقافة التلفزيونية، د. عبد الله الغذامي: 11.

8 (18) عقدة فرويد، حمودة إسماعيلي: 8

(19) الماء والأحلام، غاستون باشلار ·

(20) - (20) من الرمز الى الرمز الديني، بسام الجمل: 7.

(21) ينظر : النص العابر ، د. سمر الديوب: 263 وما بعدها.

(22) (22) (المنامات في الموروث الحكائي العربي: 53.

(23) ينظر : لغز عشتار ، فراس السواح: 43.

(24) ينظر : المصدر نفسه:73.

43 (25)

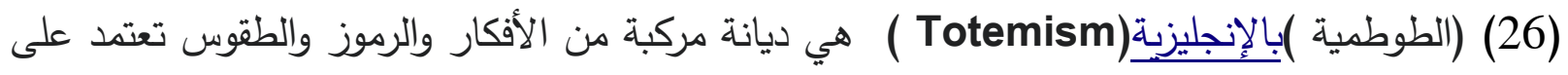

العلاقة بين جماعة إنسانية وموضوع طبيعي يسى الطوطِ. والطوطم يمكن أن يكون طائراً أو حيواناً أو نباتاً

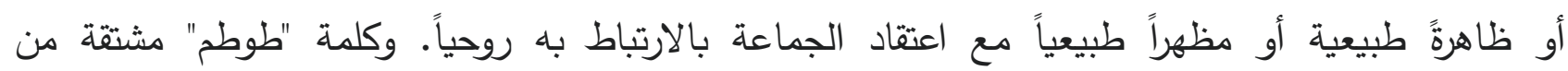

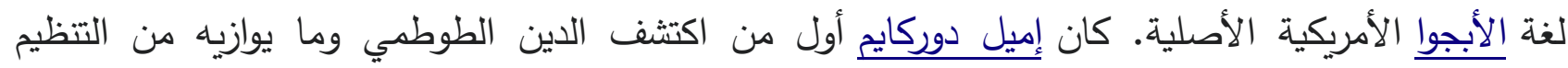

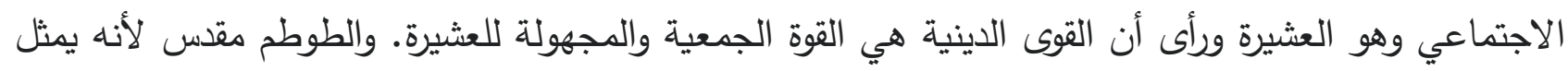

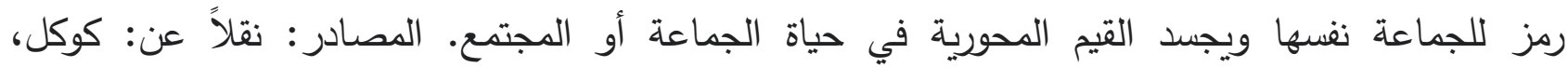


(29) ينظر: البحث عن التاريخ والمعنى في الدين، مرتثيا إلياده: 28 وما بعدها.

(30) مقدمة في أدب العراق القديم، طه باقر : 125.

(31) العقل في المجتمع العراقي بين الأسطورة والتاريخ، شاكر شاهين: 293

(32) ملحمة كلكامش، طه باقر : 86، 87

(33) سيرة ابن هشام: 11، 12 (3)

(34) ينظر : ألف ليلة وليلة.

(35) ينظر : ألف ليلة وليلة، عبد الملك مرتاض: 61 وما بعدها.

(36) تظر : رواية" النظلة والجيران"، غائب طعمة فرمان.

(37) تظظر: المصدر نفسه:101.

(38) المصدر نفسه: مقدمة د. فيصل دراج لرواية النخلة والجيران:13، 14.

(39) تتظر : رواية "الرجع البعيد"، فؤاد التكرلي.

30 (40)

(41) تنظر : رواية "سيدات زحل"، لطفية الدليمي.

(42) المصدر نفسه: 187-188

(43) تنظر : رواية "وحدها شجرة الرمان".

(44) بنية النص الكابوسي..قراءة نقدية لرواية "وحدها شجرة الرمان"، عدنان حسين أحمد، الحوار http://www.ahewar.org المتمدن

(45) ينظر : شوارع نيرودا، د. غانم حميد الزبيدي. 
هبلة أبحاث هيسان، المبلد السابع عشر، العدد الرابع والثلاثون، كانون الأول، السنة 2021 https://doi.org/10.52834/jmr.v17i34.83

(46) وحدها شجرة الرمان:10)

(47) المصدر نفسه:8-9) (-9)

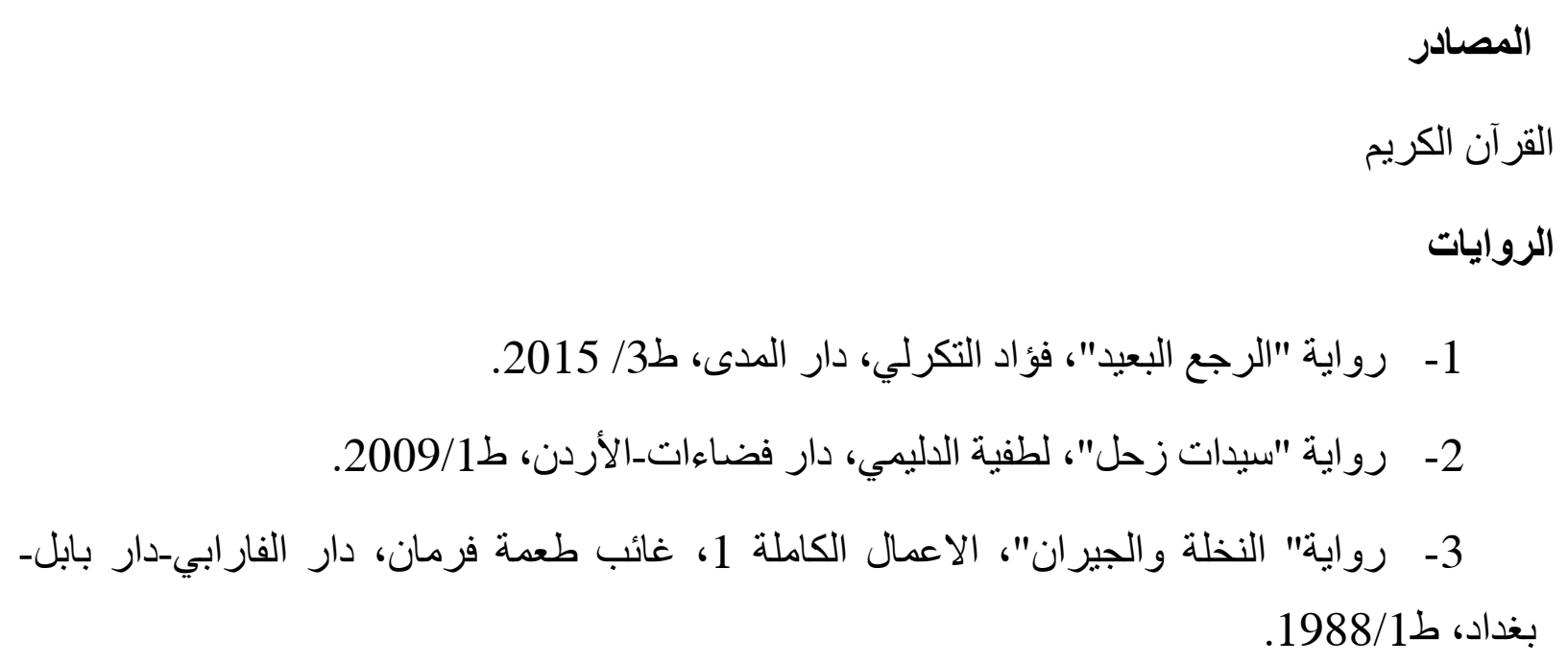




\section{هبلة أبحاث هيسان، المجلد السابع عشر، العدد الرابع والثلاثون، كانون الأول، السنة 2021 \\ https://doi.org/10.52834/jmr.v17i34.83}

4- رواية "وحدها شجرة الرمان"، سنان أنطون، المؤسسة العربية للار اسات و النشر-بيروت، ط2010/1

$$
\text { المصادر والمراجع }
$$

1- أركان الرواية، إ. م. فورستر، تر : موسى عاصي، دار جروس برس-لبنان، ط1994/1.

$$
\text { 2- ألف ليلة وليلة، مطبعة علاء-بغداد، ط1979/1. }
$$

3- ألف ليلة وليلة، عبد الملك مرتاض(دراسة سيمائية وتفكيكية لحكاية حمال بغداد)، دار الثؤون

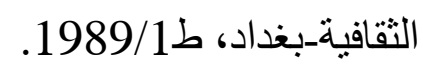

4- البحث عن التاريخ والمعنى في الدين، مرتثيا إلباده، تر: سعود المولى، المنظمة العربية

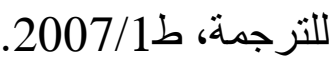

5- البناء الفني في الرواية العربية في العراق (بناء المنظور ج3)، د. شجاع العاني، دار الثؤون

$$
\text { الثقافية_العراق، ط2012/12. }
$$

6- الثقافة التلفزيونية، سقوط النخبة وبروز الثنعب، د. عبد الله الغذامي، المركز العربي الثقافي،

$$
\text { المغرب-بيروت، ط2005/2. }
$$

7- ست نزهات في غابة السرد، امبرتو إيكو، تر: سعيد بنكر اد، المركز الثقافي العربي-بيروت،

2005/1

8- السرد العربي القديم: الأنساق الثقافية و إنكاليات التأويل، د. ضياء الكعب، المؤسسة العربية

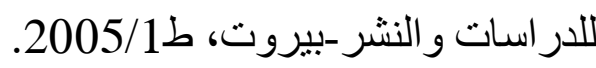

9- سيرة ابن هشام، نر: مصطفى السقا و إبراهيم الأبياري وعبد الحفيظ شلبي، دار الكتب العلمية،

$$
\text { بيروت، ط1/ }
$$

10- شوارع نيرودا "استر اتيجيات الرواية العر اقية بعد 2003. (أنثكال السلطة وصور المنقف)، د.

$$
\text { غانم حميد الزبيدي، دار أمل الجديدة، ط2019/10 }
$$

$$
\text { 11- صحيح البخاري، مج3، دار الفكر للطباعة والنشر -بيروت، } 1981
$$

$$
\text { 12- عقدة فرويد، حمودة إسماعيلي، دار الكتب_القاهرة، ط2016/1. }
$$

13- العقل في المجتمع العراقي بين الأسطورة والتاريخ "مشروع الكوفة"، شاكر شاهين، دار

$$
\text { التنوير -بيروت، ط2010/13. }
$$

14- قواعد النقد الادبي، لاسل آبر كرومبي، تر: محمد عوض محمد، دار الثؤون الثقافية-بغداد، 


\section{هبلة أبحاث هيسان، المجلد السابع عشر، العدد الرابع والثلاثون، كانون الأول، السنة 2021 \\ https://doi.org/10.52834/jmr.v17i34.83}

15- لغز عشتار "الألوهة المؤنثة وأصل الدين والأسطورة"، فراس السواح، الأعمال الكاملة 3، دار التكوين-سورية، ط2017/5.

$$
\text { 16- لسان العرب، ابن منظور ، دار صادر-بيروت، ط2000/1. }
$$

17- الماء والأحلام "دراسة عن الخيال والمادة"، غاستون باثلار، نر: علي نجيب إبراهيم،

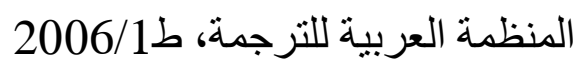

18- مسالك المعنى، سعيد بنكراد، "دراسة في بعض أنساق الثقافة العربية"، دار الحوار-سورية، .2006/1b

$$
\text { 19- مقدمة في أدب العر اق القديم، طه باقر ، دار الور اق-بغداد، ط:1010. }
$$

20- ملحمة كالكامش (وقصص أخرى عن كالكامش و الطوفان)، طه باقر، وزارة الثقافة و الاعلام-

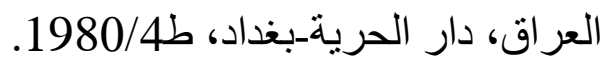

21- من الرمز الى الرمز الديني (بحث في المعنى و الوظائف و المقاربات)، بسام الجمل، كلية الآداب

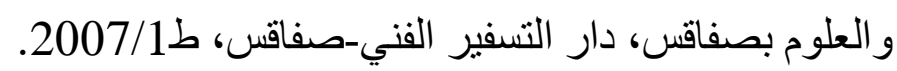

22- المنامات في الدوروث الحكائي العربي، دراسة في النص الثقافي والبنية السردية، د. دعد

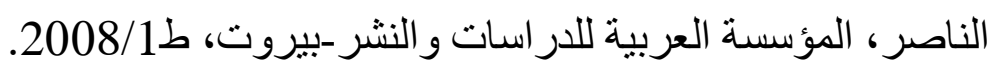

23- النص العابر، دراسات في الأدب العربي القديم، د. سمر الديوب، ط2014/1، منشورات اتحاد

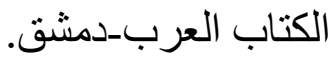

24- نقد ثقافي أم نقد أدبي، د.عبد الغذامي-د.عبد النبي اصطيف، دار الفكر-سورية، ط2004/1. 25- نقص الصورة، "تأويل بلاغة الموت1"، ناظم عودة، المؤسسة العربية للاراسات والنشر-

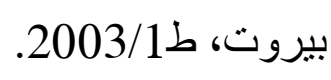

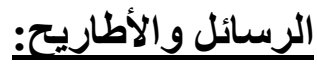

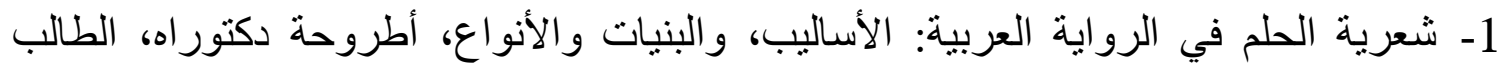

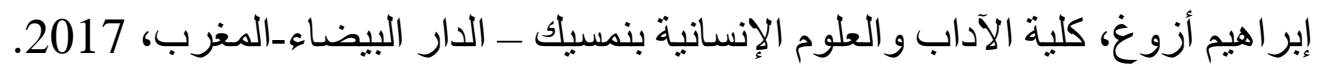

\section{الشبكة العنكبوتية:}

$$
\text { 1- - كوكل، وكيبيديا (الطوطية). }
$$

http://www.ahewar.org- الحوار المتمدن 


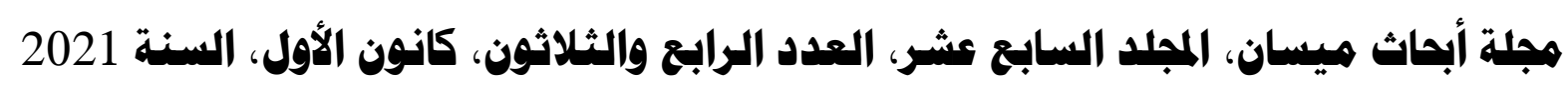
https://doi.org/10.52834/jmr.v17i34.83 